\title{
Confidence and the Transmission of Government Spending Shocks*
}

\author{
Ruediger Bachmann \\ University of Michigan and NBER \\ Eric R. Sims \\ University of Notre Dame and NBER
}

January 3, 2011

\begin{abstract}
A widespread belief among economists, policy-makers, and members of the media is that the "confidence" of households and firms is a critical component of the transmission of fiscal policy shocks into economic activity. In this paper we take this proposition to the data. We use the commonly accepted restrictions from the literature to identify government spending shocks in VARs augmented to include empirical measures of consumer or business confidence. We also estimate non-linear specifications to allow for differential impacts of government spending in recessions versus expansions. In normal times, we find that confidence falls in response to unexpected increases in government spending; during recessions it rises. In addition, the spending multiplier is much larger in recessions than in normal times. We then construct counterfactual impulse responses in which the response of confidence to government spending shocks is "shut down". Comparing the unconstrained and counterfactual responses of output allows us to determine the importance of confidence as a transmission mechanism of policy. We find that confidence is irrelevant in the transmission of government spending shocks to output in normal times, but is apparently very important during downturns. We provide some evidence that suggests this is because spending shocks during downturns lead to persistent increases in government investment relative to government consumption, whereas this is not the case in normal times.
\end{abstract}

\footnotetext{
${ }^{*}$ Contact information: rudib@umich.edu and esims1@nd.edu. We are grateful to seminar participants at Notre Dame and Rochester for helpful comments and suggestions. Any remaining errors are our own.
} 
"But the hope that monetary and fiscal policies would prevent continued weakness by boosting consumer confidence was derailed by the recent report that consumer confidence in January collapsed to the lowest level since 1992." - Martin Feldstein, Wall Street Journal, February 20, 2008

"Confidence matters independently of fundamentals!" - Roger Farmer, May 29, 2010

\section{Introduction}

A widespread belief amongst economists, policy-makers, and members of the news media is that the "confidence" of households and firms is a critical component of the transmission of policy shocks into economic activity. A sampling of quotes from economists and policymakers with wide-ranging economic and political philosophies attest to this fact (see the Appendix for more). A large literature studies the effects of fiscal and monetary policy shocks on the real economy, while a smaller though not insubstantial literature examines the effects of confidence in the economy. To our knowledge, however, no study bridges these two literatures and explicitly examines the relationship between confidence and the transmission of policy shocks. This paper fills that void.

Barsky and Sims (2010a) study the role of confidence in economic fluctuations. They show that surprise changes in consumer confidence are associated with long-lasting movements in macroeconomic aggregates. They argue that this relationship between confidence and the economy obtains because empirical measures of confidence are reflective of changes in future economic fundamentals, and in particular productivity. In contrast, they argue that autonomous fluctuations in confidence unrelated to fundamentals - i.e. what some might call "animal spirits" - are unlikely to be an important source of economic fluctuations. Their

analysis is silent on whether or not confidence may be important in the propagation of other shocks, however.

In light of the events related to the world wide economic slowdown of 2007-2010, there has been renewed interest among researchers in studying fiscal policy. In a standard neoclassical setting, it is difficult for government spending multipliers to be very large. In conventional models government spending stimulates output through a negative wealth effect, thereby limiting the size of the multiplier and eliminating any welfare justification for the increased spending in the first place. Nevertheless, an (apparently) common view is that spending multipliers might be much larger - and the welfare gains from spending positive - during periods of economic slack; some recent theoretical (Christiano, Eichenbaum, and Rebelo, 2009) and empirical (Auerbach and Gorodnichenko, 2010) work provides some evidence in 
support of this belief. As the large sampling of quotes previously alluded to suggests, there is also apparently a widespread belief that part of the transmission of fiscal stimulus into economic activity is the act of restoring or increasing confidence.

Given that there is no widely accepted channel by which confidence might matter in the transmission of fiscal policy shocks, we study this question in the context of a structural vector autoregression (VAR), which uses a minimum of theoretical restrictions to identify government spending shocks and their effects on the macroeconomy. We estimate VARs with a measure of government spending, an empirical measure of confidence (either from consumers or businesses - see Section 3.1), and macroeconomic aggregates of interest. The widely accepted identifying restriction to isolate government spending shocks is that spending shocks impact the economy immediately, whereas government spending only reacts to other shocks with a delay (e.g. Blanchard and Perotti, 2002; Ramey, 2010; Rossi and Zubairy, 2010). This amounts to a recursive identification with government spending ordered first. We implement this identifying assumption throughout the paper. This allows confidence to directly and immediately respond to surprise changes in government spending.

So as to examine the role of confidence in the transmission of spending shocks, we construct counterfactual impulse responses in which the endogenous response of confidence to government spending is "shut down". This methodology has been used previously in different contexts, particularly to study the role of the systematic component of monetary policy (e.g. Sims and Zha, 2006; Bernanke, Gertler, and Watson, 1998; and Kilian and Lewis, 2010). Construction of the counterfactuals requires creating a hypothetical sequence of some other structural shock in the system so as to zero out the impulse response of confidence to spending. We use the innovation in confidence ordered immediately after spending in a recursive identification to construct the counterfactuals. Though this innovation may not be fully structural, this approach is nonetheless informative and gives confidence its "best chance" of mattering for the transmission of spending shocks.

In conventional linear specifications of the underlying VARs we find little evidence to support the notion that confidence is an important part of the transmission of spending shocks into economic activity. In a variety of different specifications, we find that the estimated spending multipliers are generally in the neighborhood of unity and that confidence typically declines slightly on impact in response to a spending shock, though this response is economically small and statistically insignificant. The counterfactual impulse responses of macroeconomic aggregates in which the response of confidence to a spending shock is shut down are very similar to the unrestricted responses. These findings are robust to a variety of different specifications, including ones in which we directly control for anticipated changes in government spending (Ramey, 2010). In short, confidence does not appear to be a part 
of the transmission of fiscal shocks in normal times.

Given the recent theoretical and empirical work on government spending shocks having differential effects during times of economic slack, we also estimate non-linear specifications of the VAR. Following Auerbach and Gorodnichenko (2010), we allow the parameters of the VAR to differ during periods in which economic growth has been weak for an extended period of time. Similar to them, we find that spending multipliers are significantly larger during "recessions" than in normal times. ${ }^{1}$ In particular, our estimated spending multipliers are in the neighborhood of 3 during recessions. Also, we find that confidence significantly rises on impact following a positive spending shock in a recession, as opposed to falling in the linear specification.

These findings suggest that confidence may be an important part of the transmission of spending shocks during periods of economic distress. Our counterfactual analysis applied to the non-linear VAR specifications lends credence to such a conclusion; there we find that shutting down the response of confidence to a spending shock renders the output response to a spending shock close to zero. Rather than finding multipliers in the range of 3 , the estimated counterfactual spending multipliers are much closer to those estimated in the linear case (i.e. near unity).

A peculiarity in the estimated impulse responses to a spending shock during recessions is that the response of output is small on impact, and is only large after a number of quarters; this pattern of response is also evident in the estimated responses of Auerbach and Gorodnichenko (2010). Indeed, the response of output looks similar to that following a "news shock" about future productivity (Beaudry and Portier, 2006; Barsky and Sims, 2010b). To investigate this possibility further, we include in the VAR a measure of labor productivity (output per hour). We show that, in a recession, a positive government spending shock is associated with a prolonged and apparently permanent increase in productivity. We then show that constructing counterfactual responses in which the confidence response to a spending shock is shut down renders the responses of both output and productivity to a spending shock nearly zero. This suggests that it may be the effect of spending on future productivity - and not on confidence per se - that accounts for the output response to a fiscal shock in a recession.

To test this hypothesis, we then construct a "synthetic" measure of confidence that is, by construction, devoid of information about future productivity. Constructing counterfactual responses in which the response of this synthetic confidence series is shut down has no

\footnotetext{
${ }^{1}$ We use the term "recession" somewhat loosely. Following Auerbach and Gorodnichenko, 2010, we use the term to describe a period in which the two year rolling mean of real GDP growth is below a certain cutoff value.
} 
impact on the responses of output and productivity to a spending shock. This suggests that it is indeed the effect on future productivity that drives the different impulse response of output to a spending shock in a recession, not the increase in confidence per se. We provide some further evidence that the composition of government spending following a spending shock is very different in recessions as opposed to normal times. In particular, we show that there is a persistence increase in the amount of government investment relative to consumption following a spending shock in a recession; this is not the case in normal times. We hypothesize that this relative increase in investment spending drives the future increase in measured productivity, and that confidence merely reflects this change in expected future productivity. Thus, while both output and confidence do react quite differently to a spending shock during periods of recession, it appears that confidence per se is not responsible for the transmission of the fiscal shock into output.

The remainder of the paper is organized as follows. Section 2 provides some potential mechanisms for why confidence might matter for the transmission of spending shocks. Section 3 describes our data and our VAR and counterfactual methodology. It also provides some DSGE model-based simulation evidence that speaks that suitability of our empirical approach. Section 4 presents our main results. Section 5 discusses why confidence does appear to matter for the transmission of spending shocks during periods of recession. The final section concludes.

\section{Why Might Confidence Matter?}

Within the conventions of dynamic general equilibrium rational expectations macroeconomics, it is difficult to think of realistic theoretical structures which are capable of permitting an important, independent role for "confidence". The parameters of standard neoclassical models capable of generating multiple equilibria (e.g. degree of returns to scale) have been judged as empirically unrealistic (Basu and Fernald, 1997). Even under departures from full information rational expectations, general equilibrium forces and Bayesian learning render pure confidence or sentiment fluctuations quantitatively irrelevant in many contexts (Barsky and Sims, 2010). One important purpose of this paper is to attempt to use minimal theory to inform the extent to which confidence matters, which in turn can guide the development of more realistic macroeconomic models.

An old idea (Keynes, 1936) that has gained recent attention (Ackerlof and Shiller, 2008) is that "animal spirits" are central to understanding economic fluctuations. While intriguing, this idea lacks a coherent theoretical structure, and has met with limited empirical success (Barsky and Sims, 2010). Loosely speaking, the idea is that aggregate sentiment determines 
aggregate spending, which in turn determines aggregate output and employment. Fiscal or monetary shocks from the government might signal a commitment to aggregate stability, thereby raising sentiment, stimulating demand, and leading to economic expansion. This idea is related to the "sunspot" framework popularized by Farmer (1998) and others, which holds that there are, at any time, multiple aggregate equilibria. Stimulating sentiment could cause the economy to jump from a "bad" equilibrium to a "good" one.

Another related possibility includes a role for informational frictions and strategic complementarities. In a world in which households fail to perfectly observe aggregate fundamentals and use observed variables (like aggregate output) to form perceptions of the true fundamentals (see Lorenzoni, 2009). Following a recession there might be induced sluggishness - the true fundamentals might have improved but beliefs about the fundamentals are slow to catch up, hence putting a brake on the recovery. By engaging in expansionary fiscal or

monetary policies, the government may be able to convince agents that fundamentals have improved, thereby facilitating recovery.

Another possibility is that empirically measured confidence is a measure of a time-varying discount factor - periods of high confidence are periods in which households do not discount the future by much, and thus are relatively more willing to spend. If policies can lead to an increase in confidence, they might therefore stimulate demand over and above what would happen under normal transmission channels.

We do not take a stand on which, if any, of the above mechanisms are accurate. There is little agreement on how one might incorporate confidence into an economic model. As David Laibson recently wrote, "If a sample of macroeconomists were forced to write down a formal model of animal spirits, most wouldn't know where to start and the rest would produce models that had little in common" (Laibson, 2010). As noted in the Introduction, our objective here is attempt to provide some evidence using minimal theory.

\section{Data and Methodology}

In this section we describe the data used in our analysis and lay out our empirical methodology. Subsection 3.3 examines the suitability of our empirical methodology in the context of data generated from fully specified DSGE models.

\section{$3.1 \quad$ Data}

We begin with a brief analysis of our data, all of which is from publicly available sources. Real GDP and its components are taken from the BEA and are quarterly in frequency. We 
measure government spending as the sum of government consumption and gross investment. This is converted to a real measure by summing the two nominal components and deflating by the GDP deflator. We express all aggregate quantity series in per capita terms, deflating by the civilian non-institutionalized population aged 16 and over.

We draw on two sources for data on subjective measures of confidence - one for households and one for businesses. The first is the Survey of Consumers. Conducted by the Survey Research Center at the University of Michigan, the survey polls a nationally representative sample of households on a variety of questions concerning personal and aggregate economic conditions. Most answers are tabulated into qualitative categories - "good", "neutral", and "bad". Scores for each question are then tabulated as the percentage of good responses minus the percentage of bad responses. We focus on the Index of Consumer Expectations, which is an average of the scores for three different forward-looking survey questions - one concerning aggregate expectations over the next year, another aggregate expectations over the next five years, and the other concerning personal financial conditions over the next year. These data are available beginning in the first quarter of 1960 at a quarterly frequency.

We obtain survey data on business confidence from the Conference Board's CEO Confidence Survey. The Conference Boards surveys CEOs in a variety of industries on current and future economic conditions. As with the Michigan Survey, answers are tabulated into qualitative categories - "very good", "good", "neutral", "bad", and "very bad". These categories get a score of $100,75,50,25$, and 0 , respectively. The aggregate confidence score is simply the average across the respondents. Data from the survey are available at a quarterly frequency beginning in 1976.

Figures 1 and 2 plot each confidence series across time. The shaded gray areas are recessions as dated by the National Bureau of Economic Research. Both series undergo repeated dramatic swings and exhibit some of the properties that one might expect. For example, confidence is low during recessions and high during booms. The CEO confidence data appear to lead the business cycle more than do the confidence data.

\subsection{Methodology}

Much of the empirical literature on the identification of government spending shocks is (or can be) cast in a vector autoregression framework. Let $g_{t}$ be a time series measure of government spending, and let $x_{t}$ be $k \times 1$ vector of other time series of interest (e.g. output, consumption, revenue, etc.). With $Y_{t}=\left[\begin{array}{ll}g_{t} & x_{t}\end{array}\right]^{\prime}$, the VAR can be written:

$$
A(L) Y_{t}=U_{t}
$$




$$
E\left(U_{t} U_{t}^{\prime}\right)=\Omega
$$

$A(L)$ is matrix lag polynomial of order $p$, i.e. $A(L)=I-A_{1} L-A_{2} L^{2}-\ldots A_{p} L^{p}$. $U_{t}$ is a vector of innovations of conformable size, with variance-covariance matrix $\Omega$. It is necessary to orthogonalize the innovations in some way in order to be able to give them a structural interpretation. Following Blanchard and Perotti (2002), most of the literature identifies government spending shocks by ordering $g_{t}$ first in a Choleski decomposition. We will use this identifying restriction throughout the paper. It assumes that government spending shocks affect the economy immediately, whereas government spending reacts to other shocks only with a delay. For the purposes of identifying just the dynamic effects of government spending shocks, it is not necessary to take a stand on the ordering of the other variables.

A separate strand of the literature uses what we will call the "narrative approach", which can also be cast in a VAR setting. Here, however, an indicator variable enters the VAR as well, and is ordered before $g_{t}$. Ramey and Shapiro (1998) propose six "war dates" as periods where there were clear increases in government spending for reasons unrelated to the domestic economy. The war date approach appears to be heavily influenced by the Korean War date (third quarter of 1950). The remainder of the Ramey-Shapiro dates do not have any impact on measured government spending. Because our confidence data do not go back to 1950, we cannot use this approach here.

Ramey (2010) emphasizes that VAR shocks to government spending are actually predictable, which can render impulse response functions biased. She proposes a measure of anticipated government spending, $g_{t}^{a}$, that is equal to the present discounted value of future spending, based on a subjective reading of the narrative record. In order to accommodate these anticipation effects, the system to be estimated can be modified to be $Y_{t}=\left[\begin{array}{lll}g_{t}^{a} & g_{t} & x_{t}\end{array}\right]^{\prime}$. The unanticipated government spending shock is then identified as the innovation in $g_{t}$ ordered second (i.e. after $g_{t}^{a}$ ).

So as to study the role of confidence in the transmission of spending shocks, we incorporate an empirical measure of confidence into the VAR. Letting confidence be con $f_{t}$, the system can be written: $Y_{t}=\left[\begin{array}{lll}g_{t} & \operatorname{con} f_{t} & x_{t}\end{array}\right]^{\prime}$. Government spending is again ordered first. The importance of confidence in the transmission of spending shocks can be measured by constructing counterfactual impulse responses in which the endogenous response of confidence to spending shocks is "shut down". The idea of constructing counterfactual impulse responses in a VAR context was first proposed by Sims and Zha (2006) to determine how important the systematic component of monetary policy (i.e. the endogenous response of the funds rate) is for the evolution of aggregate variables. Bernanke, Gertler, and Watson (1998) use a similar approach to examine the importance of monetary policy in the transmission of oil price shocks. The basic idea is to construct a hypothetical time series of some other 
structural shock in the system so as to "zero out" the impulse response of confidence to the spending shock, and then to look at how different the other impulse responses are relative to the baseline case.

While the ordering of confidence relative to the other variables in $x_{t}$ does not matter for looking at the impulse responses to spending shocks, it does matter for the construction of counterfactuals. This is because we must use an orthogonalized shock from the system in order to shut down the confidence response to spending shocks. Following Barsky and Sims (2010), we order confidence before the other aggregate variables in $x_{t}$, meaning that confidence shocks affect all variables in $x_{t}$ immediately, and use this shock to construct the counterfactuals. As noted by Barksy and Sims (2010), the confidence innovation so ordered in a Choleski decomposition may not have a purely structural interpretation. Nevertheless, this approach gives confidence its "best chance" of being important in the transmission of spending shocks.

Formally, let $\varepsilon_{t}$ be a vector of orthogonal shocks such that $U_{t}=B \varepsilon_{t}$. Under the recursive identification, $B$ is lower triangular and satisfies $B B^{\prime}=\Omega$ after normalizing the variancecovariance matrix of structural shocks to be an identity matrix. The impulse response function, which is the same as the structural moving average representation, is:

$$
\begin{gathered}
Y_{t}=C(L) \varepsilon_{t} \\
C(L)=A(L)^{-1} B
\end{gathered}
$$

We will use the notation that $C_{i, j}(h)$ denotes the impulse response of variable $i$ at horizon $h$ to a unit shock $j$ at time $t$. Let government spending by indexed by $i=1$ and confidence by $i=2$. The impulse response of confidence to a spending shock is then $C_{2,1}(h)$. We need to come up with a sequence of confidence shocks (i.e. $\varepsilon_{2, t+h}$ ) so as to zero this response out at all horizons. The required sequence of shocks can be computed recursively as follows:

$$
\begin{array}{r}
C_{2,1}(h)=0 \quad \forall h \geq 0 \\
\Leftrightarrow \\
\varepsilon_{2, t}=-C_{2,1}(0) / C_{2,2}(0) \\
\varepsilon_{2, t+h}=\frac{-C_{2,1}(h)-\sum_{j=1}^{h} C_{2,2}(h-j) \varepsilon_{t+h-j}}{C_{2,2}(0)} \quad \forall h \geq 1
\end{array}
$$

Given the time series of counterfactual confidence shocks, the counterfactual impulse re- 
sponses of the full system, $\widetilde{C}_{i, 1}(h)$ to the government spending shock can be written:

$$
\widetilde{C}_{i, 1}(h)=C_{i, 1}(h)+\sum_{j=0}^{h} C_{i, 2}(h-j) \varepsilon_{2, t+j} \quad \forall h \geq 0
$$

Old Keynesian intuition and some recent theoretical work (Christiano, Eichenbaum, and Rebelo, 2009, and Woodford, 2010) both suggest that fiscal policy may be more potent when the economy is experiencing significant slack. So as to allow for this possibility, we also consider a non-linear VAR specification similar to Auerbach and Gorodnichenko (2010). Following them, let $z_{t}$ be a seven quarter moving average of real GDP growth, normalized to have mean zero and re-scaled to have unit variance. This series can be interpreted as a measure of the current state of the economy. We construct the following function:

$$
f\left(z_{t}\right)=\frac{\exp \left(-\gamma z_{t}\right)}{1+\exp \left(-\gamma z_{t}\right)} \quad \gamma>0
$$

The function $f\left(z_{t}\right)$ is thus bound between 0 and 1. $f\left(z_{t}\right) \approx 1$ means that $z_{t}$ is very negative, while $f\left(z_{t}\right) \approx 0$ means that $z_{t}$ is very positive. As in Auerbach and Gorodnichenko (2010), we calibrate $\gamma=1.5$ and define a "recession" as a period in which $f\left(z_{t}\right)>0.8$. This lines up well with NBER-defined recessions, as shown in Figure 3, which plots $f\left(z_{t}\right)$ against time, with the shaded gray regions denoting NBER defined recessions.

Our non-linear system can be written (again with $\left.Y_{t}=\left[\begin{array}{lll}g_{t} & \operatorname{con} f_{t} & x_{t}\end{array}\right]^{\prime}\right)$ :

$$
\begin{gathered}
Y_{t}=A_{1}(L) Y_{t-1}+A_{2}(L) Y_{t-1} z_{t-1}+A_{3}(L) Y_{t-1} z_{t-1}^{2}+U_{t} \\
E\left(U_{t} U_{t}^{\prime}\right)=\Omega_{n} \text { if } f\left(z_{t}\right) \leq 0.8 \\
E\left(U_{t} U_{t}^{\prime}\right)=\Omega_{r} \text { if } f\left(z_{t}\right)>0.8
\end{gathered}
$$

In words, $Y_{t}$ follows an autoregressive process depending on its own lags, its own lags interacted with $z_{t}$, and its own lags interacted with $z_{t}^{2}$. These interaction terms allow the AR coefficients to vary with the state of the economy. We assume that the innovations, $U_{t}$ have a conditionally heteroskedastic variance-covariance matrix. In particular, we assume that the variance-covariance matrix can take on two different values: one in normal times, and one in recessions. The above specification has the appeal that it nests the linear case if $\Omega_{n}=\Omega_{r}$ and $A_{2}(L)=A_{3}(L)=0$. The ordering of the variables in the Choleski identification and the construction of counterfactuals is the same as in the linear case. A complication is that impulse responses are now state dependent, and there is feedback between the impulse 
responses and the level of $z_{t}$. To work around the latter issue, we assume that $E_{t} z_{t+j}=\rho^{j} z_{t}$, where $\rho$ is estimated from a univariate autoregression of $z_{t}$. To deal with the state dependence, when looking at impulse responses in a recession, we fix $z_{t}$ equal to its sample average conditional on $f\left(z_{t}\right)>0.8$.

\subsection{Suitability}

We now briefly present some model-based evidence that our VAR and counterfactual methodologies are appropriate and likely to work well in practice. We study a simple DSGE model with government spending shocks. We consider two parameterizations: one in which there is a unique equilibrium and confidence merely reflects fundamentals, and another in which there are multiple equilibria and confidence pins down the particular equilibrium.

Households seek to maximize the present discounted value of lifetime utility from consumption and work:

$$
\sum_{j=0}^{\infty} \beta^{j} E_{t}\left(\ln c_{t+j}-\theta n_{t+j}\right)
$$

Following Thomas (2004), firms produce output according to the following production technology:

$$
y_{t}=z_{t} k_{t}^{a} n_{t}^{b}\left(\bar{k}_{t}^{a \gamma} \bar{n}_{t}^{b \gamma}\right)
$$

$\bar{k}_{t}$ and $\bar{n}_{t}$ are the economy-wide averages of the capital stock and labor input. If $\gamma>0$, then there is a production externality and there may be multiple equilibria. If $\gamma=0$ and $b=1-a$, then the model reduces to the standard real business cycle model.

Aggregate TFP and government spending obey AR(1) processes in the logs:

$$
\begin{aligned}
& \ln z_{t}=\rho_{z} \ln z_{t-1}+e_{a, t} \\
& \ln g_{t}=\left(1-\rho_{g}\right) \ln g^{*}+\rho_{g} \ln g_{t-1}+e_{g, t}
\end{aligned}
$$

The accounting identity is $y_{t}=c_{t}+k_{t+1}-(1-\delta) k_{t}+g_{t}$. We incorporate "confidence" into the model in the following way: we assume that it follows a univariate $\operatorname{AR}(1)$ process with an innovation equal to a linear combination of the two structural disturbances and its own "noise" term: 


$$
\operatorname{con} f_{t}=\rho_{c} \operatorname{con} f_{t-1}+\phi_{1} e_{a, t}+\phi_{2} e_{g, t}+e_{c, t}
$$

This specification is similar to the structural model in Barsky and Sims (2010).

We fix the following parameter values: $\rho_{g}=0.97, \rho_{z}=0.95, \beta=0.989, \delta=0.25$, $\rho_{c}=0.91, \phi_{1}=1$, and $\phi_{2}=0.5$. We fix $g^{*}$ such that government spending is 20 percent of output in steady state. We set the standard deviation of the confidence specific shock to 0.01 , the standard deviation of the TFP shock to 0.007 , and the standard deviation of the confidence noise shock to 0.07 . We consider two cases for the remaining parameters. In one, $b=1-a$ and $\gamma=0$. In this case, confidence is reflective of fundamentals but otherwise has no impact on the other variables of the model. In the other case, we set $a=0.23, b=0.7$, and $\gamma=0.7234$. These parameter values are taken from Farmer and Guo (1994), and give rise to multiple equilibria. We assume that the level of confidence pins down the economy's equilibrium. In practice, this means that there is an error in the dynamic Euler equation equal to the innovation in measured confidence. This means that confidence is both reflective of economic fundamentals and has an important causal role to play in the evolution of the endogenous variables of the model. It also changes the nature of the response to government spending - in particular, because increases in government spending raise confidence, they cause the economy to coordinate on a "better" equilibrium, and output expands by significantly more than it would in the absence of the multiplicity of equilibria.

We conduct the following experiment to examine the suitability of our empirical approach. We simulate data from both cases of the model, drawing shocks from normal distributions. Then for each simulated data set we estimate a three variable VAR with government spending, confidence, and output. We estimate the VAR in the levels of the variables with four lags. We orthogonalize the innovations in that order using a Choleski decomposition. This ordering is consistent with the implications of the structural model and is the same empirical specification which we use in Section 4. We simulate 500 different data sets with 200 observations each. For each simulated data set we compute both unrestricted and counterfactual impulse responses to a government spending shock and then we average these over the simulations.

Figure 4 shows some results for the case with a unique equilibrium. The solid dark line shows the theoretical impulse response to a government spending shock and the dashed line shows the average estimated impulse responses across the simulations. The dotted line shows the average estimated counterfactual impulse responses in which confidence is held fixed. We observe that the estimated VAR does a good job at estimating the true impulse responses, though there are slight downward biases in the responses at longer horizons due 
to downward biased estimates of autoregressive roots. The counterfactual responses of both government spending and output lie on top of their estimates from the unrestricted case. This is to be expected, since in this model confidence has no effect on either government spending or output.

Figure 5 shows results from the case with multiple equilibria. The labeling of the responses is the same as in Figure 4. Once again, we observe that the estimated VAR does a good job in capturing the model's impulse responses. There is an important difference here relative to Figure 4, however. In the counterfactual case, the response of output to government spending is essentially zero at all horizons when the response of confidence to spending is shut down. This is precisely what would happen in the model, since confidence pins down the equilibrium.

In short, our simulation results suggest that our VAR approach is capable of doing a good job at identifying impulse responses to government spending shocks, and that our counterfactual approach is capable of addressing the question of whether confidence is an important part of the transmission mechanism of spending shocks.

\section{Results}

For our benchmark estimation, we estimate a system with the log real government spending (consumption expenditures plus investment), a measure of confidence, and log real GDP. In the notation of the previous section, $x_{t}=y_{t}$. Including additional variables in $x_{t}$ does not affect the main results; we prefer to keep $x_{t}$ small because our non-linear specifications place large burdens on the data. ${ }^{2}$ We estimate the system in the levels of the variables with four lags. Four lags is common with quarterly data and is consistent with a number of lag order selection criteria. Government spending and output are likely cointegrated; estimation in levels preserves any cointegrating relationship and will therefore yield consistent estimates of impulse response functions. The alternative of estimating vector error correction models (VECMs) yields similar results. Inference is conducted via Kilian's (1998) bias-corrected bootstrap after bootstrap.

Figure 6 shows impulse responses using the consumer confidence data, which go back to 1960. The solid lines are the estimated responses to a one standard deviation government spending shock. The shaded gray regions are the 90 percent confidence bands. Government spending follows a hump-shaped response but is nevertheless fairly persistent. Output rises

\footnotetext{
${ }^{2}$ In the benchmark system there are $p \times q$ autoregressive parameters to estimate, where $p$ is the lag length and $q$ is the number of variables. In the non-linear estimation there are $3 \times p \times q$ parameters to estimate, which grows quickly with $q$.
} 
by about 0.2 percent on impact before reverting back to its pre-shock value. Confidence actually falls on impact before rising slightly a few quarters later. This response is never significantly different from zero in the statistical sense.

The dashed lines in the figure show the counterfactual impulse responses when the response of confidence is shut down, where we use confidence innovations ordered second in a Choleski decomposition to construct the counterfactuals. The counterfactual responses are very similar to the unconstrained impulse responses, and the hypothesis that they are the same cannot be reject statistically at any conventional significance level. This is not surprising given that confidence does not respond much to the government spending shock in the first place.

Figure 7 repeats this exercise, this time using the Conference Board's CEO confidence index in lieu of the Michigan consumer confidence series. Given data limitations, the sample period here only begins in the second quarter of 1976. The responses are nevertheless very similar. Government spending follows a hump-shaped response to a spending shock, confidence initially falls and then rises, and the initial impact on output is an increase of about 0.2 percent. As in the case with consumer confidence, the counterfactual impulse responses to the spending shock when confidence is held fixed are very similar to the unconstrained responses.

Next we present some quantitative evidence in the form of spending multipliers. We present two different versions of the multiplier: the "impact" multiplier and the "max" multiplier. The impact multiplier is simply the impact response of output divided by the impact response of government spending to a spending shock. The max multiplier is the maximum response of output (taken over the first twenty quarters) divided by the impact response of government spending. As both government spending and output enter the estimated VARs in logs, these multipliers would have interpretations as elasticities. So as to put the multipliers in the more familiar dollar terms, we multiply them by the sample average ratio of output to spending. As such, the numbers in the table have the interpretation as the dollar effect on output of a one dollar increase in government spending.

Table 1 shows the estimated multipliers. The first column, labeled "Linear", gives the estimated spending multipliers in both the system estimated with consumer and the system with estimated with CEO confidence. The numbers in brackets are the 90 percent bootstrap confidence bands. The estimated multipliers are all in the neighborhood of one, which is in line with most previous estimates (e.g. Ramey, 2010). The impact and max multipliers are both about 0.75 for the system with consumer confidence, suggesting that a one dollar increase in spending generates about 75 cents in extra output. In the system with CEO confidence, the impact multiplier is 1 and the max multiplier is 1.5; the difference in multipliers 
between the two systems results primarily from the different sample sizes used (1960 on for consumers and 1976 on for CEOs). The second column, labeled "counterfactual", gives the estimated counterfactual multipliers when confidence is held fixed following a government spending shock. These are very similar to the unrestricted cases, and one cannot reject the hypothesis that they are equal.

We conduct a number of additional robustness checks on our basic results. As emphasized by Ramey (2010) and discussed in Section 3, there may be important anticipation effects that could bias the estimated impulse response functions. To that end, we include Ramey's (2010) government spending news variable in the VAR, ordering it first in a Choleski decomposition. The impulse responses to the unanticipated government spending shock (the innovation in $g_{t}$ ordered second) are very similar to what is shown in Figures 6 and 7 . The inclusion of additional variables other than just output in the block of variables $x_{t}$ also does not substantively affect our conclusions or our estimates of spending multipliers. As we are primarily interested in the magnitude of the spending affect on output and its relationship with confidence, and not whether the responses of consumption and wages look more Keynesian or more neoclassical, we do not report these results here. ${ }^{3}$ Our results are also qualitatively unaffected by different lag lengths or different assumptions concerning common trends (e.g. estimating a VECM instead of a VAR in levels or including a deterministic time trend).

In summary, the evidence from the linear VAR specifications suggests that confidence is not an important part of the transmission of government spending shocks into output. Point estimates suggest that confidence falls on impact in response to spending, though this response is insignificant. Shutting the confidence response down with offsetting "confidence shocks" does not substantively alter the impulse response of output to spending. The spending multipliers are always estimated to be in the neighborhood of one, regardless of whether confidence is allowed to react to the spending shock or not.

Next we examine results from the non-linear specification detailed in Section 3.2. As in Auerbach and Gorodnichenko (2010), we find that the output effects of government spending are much larger in recessions than normal times. Figure 8 shows impulse responses to a spending shock in a recession, with the size of the shock normalized to be the same as in the linear system. The dashed lines are the impulse responses in a recession, the solid lines are the responses estimated from the linear system, and the shaded gray areas are the confidence bands from the linear estimation. Two main features stand out. First, the output response

\footnotetext{
${ }^{3}$ See, for example, Blanchard and Perotti (2002) or Ramey (2010) for a discussion of whether the impulse responses of other variables - like consumption, hours, and wages - are consistent with the predictions of a standard neoclassical mode.
} 
to a spending shock is very different in a recession than in normal times. Interestingly, most of the difference is at longer horizons rather than shortly after the spending shock. This pattern of response is identical to the responses estimated by Auerbach and Gorodnichenko (2010). Secondly, consumer confidence increases on impact and is persistently high following a spending shock, as opposed to declining slightly. This impulse response is statistically different from the linear case. Figure 9 is the same picture using CEO confidence. The pattern of responses is very similar - confidence rises in response to a spending shock and the output response is much larger than in the linear case, particularly at longer horizons.

Having established that output and confidence respond quite differently to government spending shocks in recessions relative to normal times, we next investigate how important the confidence response is for the output response in recessions. Figures 10 and 11 show impulse responses and counterfactual responses to spending shocks in recessions, for systems estimated with consumer and CEO confidence, respectively. The shaded gray regions are the confidence bands for the impulse responses to a spending shock in recessions. ${ }^{4}$ Given that we effectively have few observations for recessions, these bands are significantly wider than in the linear case. The results are nevertheless interesting and instructive. For both the cases with consumer confidence (Figure 10) and CEO confidence (Figure 11), we see that shutting down the response of confidence to a spending shock renders the output response essentially zero at all horizons. Put differently, it appears as though confidence is critical to the transmission of the spending shock to output in recessions. The last two columns of Table 1 quantify this finding. Although the impact multipliers in recessions are about the same as their linear counterparts, the max multipliers for government spending are around 3 , or about 3 times as large as in the linear case. These numbers are line with those reported in Auerbach and Gorodnichenko (2010). The counterfactual multipliers, in contrast, are significantly smaller and close to zero. While the confidence bands are indeed wide, the evidence suggests that spending multipliers are much larger in recessions than in normal times and that confidence is somehow related to that.

\section{$5 \quad$ Why Does Confidence Matter?}

The evidence from the previous section suggests the confidence of households and firms is somehow related to the transmission of government spending shocks into output during times

\footnotetext{
${ }^{4}$ These confidence bands are constructed differently from the confidence bands in the linear case so as to preserve the heteroskedasticity of the innovations. In particular, we re-sample the growth rates of each of the variables according to a block bootstrap with a 20 period window. We then do a double bootstrap on the cumulated sums of the re-sampled growth rates to construct bias corrections and then again to get bands for the impulse responses.
} 
of economic slack. In this section we seek a deeper explanation for this finding.

Barsky and Sims (2010) show that unexpected increases in measured consumer confidence are associated with slowly-building and persistent increases in output, consumption, and productivity. They argue that confidence innovations must reflect news about future economic fundamentals. While they cannot necessarily rule out that this news is observed with substantial noise (they refer to the noise as "animal spirits"), they show that their estimated impulse responses to confidence innovations are inconsistent with animal spirits being an important driving force of aggregate data.

In the spirit of their analysis, we include an empirical measure of productivity into the set of variables $x_{t}$ in our estimated VAR. As a first pass, we simply use the BLS measure of output per hour in the non-farm business sector. Formally, the VAR to be estimated includes government spending, confidence, output, and productivity. Given the longer sample size, we focus in this section on the results using consumer confidence. Figure 12 shows responses to the spending shock from this four variable system, both for the linear case (solid line) and the recession case (dashed lines). As in the smaller system, confidence increases on impact in a recession and the output response is much larger, particularly at long horizons. Interestingly, the productivity response to a spending shock is much the same as the output response - essentially zero on impact followed by a large and protracted increase. Put differently, a government spending shock in a recession apparently leads to a very persistent and economically large increase in productivity. In contrast, the response of productivity to a spending shock in normal times is roughly zero at all horizons.

Figure 13 shows the estimated impulse responses to a spending shock in a recession as well as the counterfactual responses when confidence is held fixed. We again use confidence innovations ordered second in a Choleski decomposition in order to construct the counterfactuals. As in Figures 10 and 11, shutting the confidence response down renders the output response to a spending shock essentially zero at all horizons. Here we also observe that shutting confidence down renders the productivity response to a spending shock close to zero at all horizons. In light of Barsky and Sims's (2010) conclusions about the relationship between productivity and confidence, this should not be surprising. Confidence shocks portend future increases in productivity; using these confidence shocks to construct the counterfactuals will work to offset the productivity response to a spending shock at longer horizons, and thereby also works to shut down the output response.

These results are suggestive that it is perhaps not confidence per se that is an important part of the transmission of spending shocks during recessions, but rather it is the increase in future productivity. Measured confidence may merely be informative about this future increase in productivity, and constructing counterfactuals using confidence shocks may be (in- 
correctly, for our purposes) shutting down the productivity response. To determine whether confidence per se matters for the transmission of spending (through, for example, an "animal spirits" channel), we would ideally like to construct counterfactual impulse responses using confidence innovations which are uninformative about future productivity.

We deal with this issue in the following way. Barsky and Sims (2010b) identify a time series of "news shocks" about future total factor productivity; these news shocks are uncorrelated with current TFP but predict future TFP and are strongly correlated with consumer confidence innovations. ${ }^{5}$ Using their estimated parameters and time series of news shocks, we can construct a synthetic confidence series that has been purged of any direct influence from news shocks. See the Appendix for details on the construction of this synthetic series. We re-estimate the system above using the synthetic measure of consumer confidence in lieu of the baseline series. The system features government spending, synthetic confidence, output, and labor productivity. The basic features from the above systems are still in place. In normal times, the spending multiplier is around 1, confidence falls in response to spending, and productivity does not react. In recessions the multiplier is much larger (driven by the responses at longer horizons), the synthetic confidence series rises on impact, and productivity increases over longer horizons. These features are evident in Figure 14, which shows the recession impulse responses as solid lines and confidence bands in shaded gray. The counterfactual impulse responses shutting down the response of the synthetic confidence series are depicted by the dashed lines. Here we see that shutting confidence down with offsetting confidence shocks has almost no effect on the output and productivity responses to a spending shock in a recession. Put differently, using confidence shocks devoid of any information about future productivity has no effect on the output impulse response to a spending shock. Confidence per se does not appear to be an important part of the transmission of spending shocks into output.

The evidence presented thus far suggests that government spending shocks have differential effects on both confidence and output in recessions relative to normal times, and that this differential effect is driven by an effect of spending on productivity. We investigate this link further by decomposing government spending into its two main constituent components - consumption and investment. We estimate a four variable system featuring the following variables: total government spending, consumer confidence, real output, and the log ratio of government investment expenditure to consumption expenditure (here we use the raw, not synthetic, confidence series). Our hypothesis is that the mix of investment and consumption expenditures is different between recessions and normal times, and that this may account

\footnotetext{
${ }^{5}$ given the effective size of our non-linear VARs, this two step procedure is much more straightforward and reliable to implement than would be a simultaneous identification of news shocks.
} 
for the differential responses of confidence and productivity.

Figure 15 shows impulse responses from the linear system to a spending shock; the dashed lines show the counterfactual responses when confidence is shut down. The pattern of responses for output and confidence are similar to before. We see that the ratio of investment to consumption expenditure rises on impact following a spending shock, but thereafter quickly reverts back to its pre-shock level. Figure 16 shows the responses from the same system to a spending shock in a recession (dashed line). Here the response of the government investment/consumption ratio is quite different in a recession. Rather than reverting back to its pre-shock value, the investment/consumption ratio remains permanently higher following a spending shock during a recession. This suggests that there is an important difference in the longer term consequences for the composition of government spending following a spending shock in a recession. Figure 17 shows impulse responses in a recession for the counterfactual case in which the confidence response is shut down. Here we see that shutting confidence down renders the output response to a spending shock essentially zero at all horizons and leaves the response of the investment/consumption ratio far more transitory (and similar to the linear case).

In summary, government spending shocks in recessions seem to be associated with a permanently elevated level of investment expenditure relative to consumption expenditure. It is easy to envision scenarios of why this would lead to productivity gains in the private sector. This connection between government spending, the composition of government spending, and productivity seems to be the key to the relationship between confidence and the transmission of spending shocks in a recession. Confidence does not seem to be an important part of the transmission of spending shocks per se, but rather reflects information about future productivity gains that will result as a consequence of the extra government spending.

\section{Conclusion}




\section{References}

[1] Ackerlof, George and Robert Shiller. Animal Spirits. Princeton, NJ: Princeton University Press, 2008.

[2] Barsky, Robert B. and Eric Sims. "Information, Animal Spirits, and the Meaning of Innovations in Consumer Confidence." NBER WP \#15049, 2010.

[3] Basu, Susanto and John Fernald. "Returns to Scale in US Production: Estimates and Implications." Journal of Political Economy 105, 249-283, 1997.

[4] Bernanke, Ben, Mark Gertler, and Mark Watson. "Systematic Monetary Policy and the Effects of Oil Price Shocks." Brookings Papers on Economic Activity, 1, 91-157, 1998.

[5] Blanchard, Olivier and Roberto Perotti. "An Empirical Characterization of the Dynamic Effects of Changes in Government Spending and Taxes on Output." Quarterly Journal of Economics. 107, 2002, 1329-12368.

[6] Campbell, John and N. Gregory Mankiw. "Consumption, Income, and Interest Rates: Reinterpreting the Time Series Evidence." NBER Macroeconomics Annual, 1989.

[7] Carroll, Christopher, Jeffrey Fuhrer and David Wilcox. "Does Consumer Sentiment Forecast Household Spending? If so, Why?" American Economic Review, 1994, 13971408.

[8] Christiano, Lawrence, Martin Eichenbaum, and Charles Evans. "Monetary Policy Shocks: What Have We Learned and to What End?" Handbook of Macroeconomics, 1999.

[9] Christiano, Lawrence, Martin Eichenbaum, and Charles Evans. "Nominal Rigidities and the Dynamic Effects of a Shock to Monetary Policy." Journal of Political Economy, 2006, 514-558.

[10] Christiano, Lawrence, Martin Eichenbaum, and Sergio Rebelo. "When is the Government Spending Multiplier Large?" NBER WP \#15394, 2009.

[11] Farmer, Roger. The Macroeconomics of Self-Fulfilling Prophecies. Boston, MA: MIT Press, 1998.

[12] Faust, Jon. "The Robustness of Identified VAR Conclusions About Money." CarnegieRochester Conference Series on Public Policy, 49, 1998, 207-244. 
[13] Faust, Jon and Eric Leeper. "When Do Long Run Identifying Restrictions Given Reliable Results?" Journal of Business and Economics Statistics, 1997, 345-353.

[14] Keynes, John Maynard. The General Theory. 1936.

[15] Kilian, Lutz. "Small Sample Confidence Intervals for Impulse Response Functions." Review of Economics and Statistics, 1998, 218-230.

[16] Kilian, Lutz and Logan Lewis. "Does the Fed Respond to Oil Price Shocks?" University of Michigan Working Paper, 2009.

[17] Lorenzoni, Guido. "A Theory of Demand Shocks." American Economic Review 99: 2050-2084, 2009.

[18] Ramey, Valerie. "Identifying Government Spending Shocks: It's All in the Timing." NBER WP \#15464, 2009.

[19] Matsusaka, J.G. and Argia Sbordonne. "Consumer Confidence and Economic Fluctuations." Economic Inquiry. 1994.

[20] Mountford, Andrew and Harald Uhlig. "What are the Effects of Fiscal Policy Shock?" Journal of Applied Econometrics, 24, 2009, 960-992.

[21] Romer, Christina and David Romer. "Does Monetary Policy Matter? A New Test in the Spirit of Friedman and Schwartz." NBER Macroeconomics Annual, 1989.

[22] Romer, Christina and David Romer. "A New Measure of Monetary Policy Shocks: Derivation and Implications." American Economic Review, 94, 1055-1084.

[23] Romer, Christina and David Romer. "The Macroeconomic Effects of Tax Changes: Estimates Based on a New Measure of Fiscal Shocks." American Economic Review, forthcoming, 2009 (WP version 2007).

[24] Shapiro, Matthew and Valerie Ramey. "Costly Capital Reallocation and the Effects of Government Spending." Carnegie-Rochester Conference Series on Public Policy, 48, 1998, 145-194.

[25] Sims, Christopher and Tao Zha. "Does Monetary Policy Generate Recessions?" Macroeconomic Dynamics, 10, 2006, 231-272. 


\section{Appendix: Quotes}

"We must be certain that programs to solve the current financial and economic crisis are large enough, and targeted broadly enough, to impact public confidence." - Robert Shiller

"Yale's Bob Shiller argues that confidence is the key to getting the economy back on track. I think a lot of economists would agree with that." - N. Gregory Mankiw

"Enacting such a conditional stimulus would have two desirable effects. First, it would immediately boost the confidence of households and businesses since they would know that a significant slowdown would be met immediately by a substantial fiscal stimulus." - Martin Feldstein

"But the hope that monetary and fiscal policies would prevent continued weakness by boosting consumer confidence was derailed by the recent report that consumer confidence in January collapsed to the lowest level since 1992." - Martin Feldstein

"The economy is stagnant because of a lack of confidence in the future." - Russell Roberts ". . . that at some point, people could lose confidence in the U.S. economy in a way that could actually lead to a double-dip recession." - President Barack Obama

"The stimulus was too small, and it will fade out next year, while high unemployment is undermining both consumer and business confidence." - Paul Krugman

"It's only an attempt to perhaps provide a bit of additional confidence, a bit of additional assurance or a bit of additional certainty to the markets about the Federal Reserve's long-term objective." - Ben Bernanke

"Economic activity in the United States turned up in the second half of 2009, supported by an improvement in financial conditions, stimulus from monetary and fiscal policies, and a recovery in foreign economies. These factors, along with increased business and household confidence, appear likely to boost spending and sustain the economic expansion." - Ben Bernanke

"Confidence today will be enhanced if we put measures in place that assure that the coming expansion will be more sustainable and fair in the distribution of benefits than its predecessor." - Larry Summers

"President Obama's top priority has been to stop the vicious cycle of economic and financial collapse, stem the historic rate of job loss, restore confidence and put the economy on a path 
to recover." - Larry Summers

"Others say that we should have a fiscal stimulus to 'give people confidence,' even if we have neither theory nor evidence that it will work." - John Cochrane

"The subsequent global sell-off in equity markets suggested that governments would need to take action with more immediate impact to restore confidence in the markets." - James Bullard 
Table 1: Spending Mulipliers

\begin{tabular}{|l|l|l|l|l|}
\hline & Linear & Counterfactual & Recession & Counterfactual \\
\hline Consumer & & & & \\
\hline Impact Multiplier & 0.735 & 0.811 & 0.664 & 0.540 \\
\hline & {$[0.35,1.15]$} & & {$[-0.33,1.91]$} & \\
\hline Max Multiplier & 0.735 & 0.811 & 3.717 & 0.540 \\
\hline & {$[0.43,2.33]$} & & {$[0.10,7.47]$} & \\
\hline CEO & & & & \\
\hline Impact Multiplier & 1.011 & 1.052 & 0.517 & 0.200 \\
\hline & {$[0.46,1.59]$} & & {$[-0.58,2.46]$} & \\
\hline Max Multiplier & 1.522 & 1.080 & 2.930 & 0.200 \\
\hline & {$[0.69,4.07]$} & & {$[0.26,14.1]$} & \\
\hline
\end{tabular}

This table shows spending multipliers from the benchmark three variable systems described in Section 4 . The "linear" column corresponds to the linear specification, and the following "counterfactual" column is the counterfactual multiplier in the linear specification. The "recession" column corresponds to the recession estimates from the non-linear specification, and the following counterfactual column presents multipliers in the counterfactual case for a recession. The numbers have the interpretation as the dollar impact on output (either on impact or the maximum effect over 20 quarters) for a one dollar increase in spending. The numbers in brackets are 90 percent bootstrap confidence intervals. 
Figure 1: Consumer Confidence

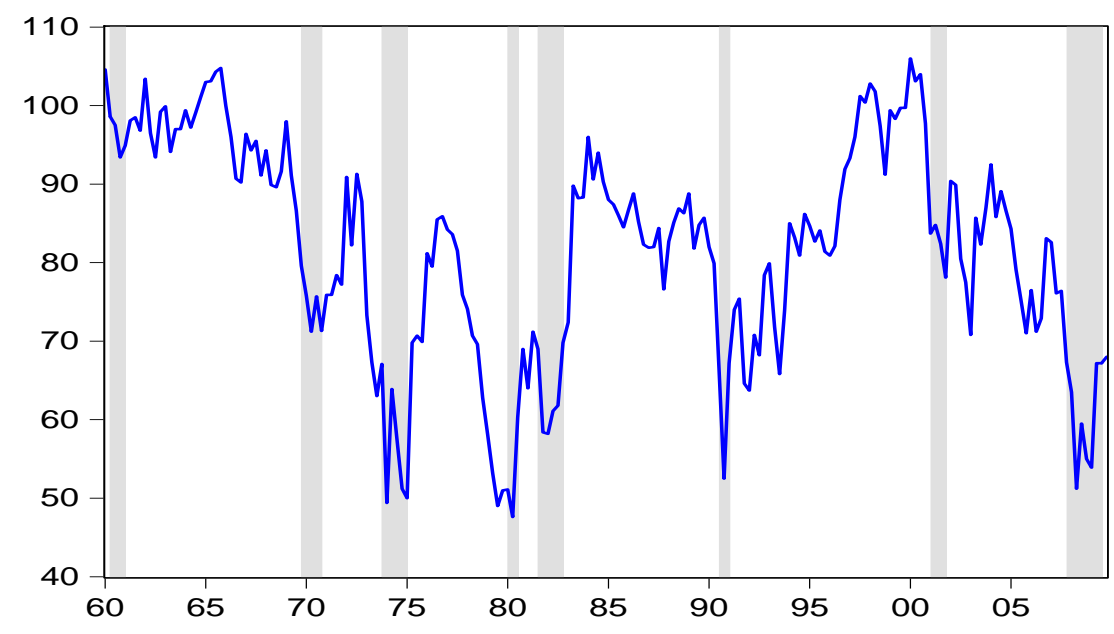

This figure plots the forward-looking index from the Michigan Survey of Consumers. Shaded gray areas are recessions as defined by the NBER.

Figure 2: CEO Confidence

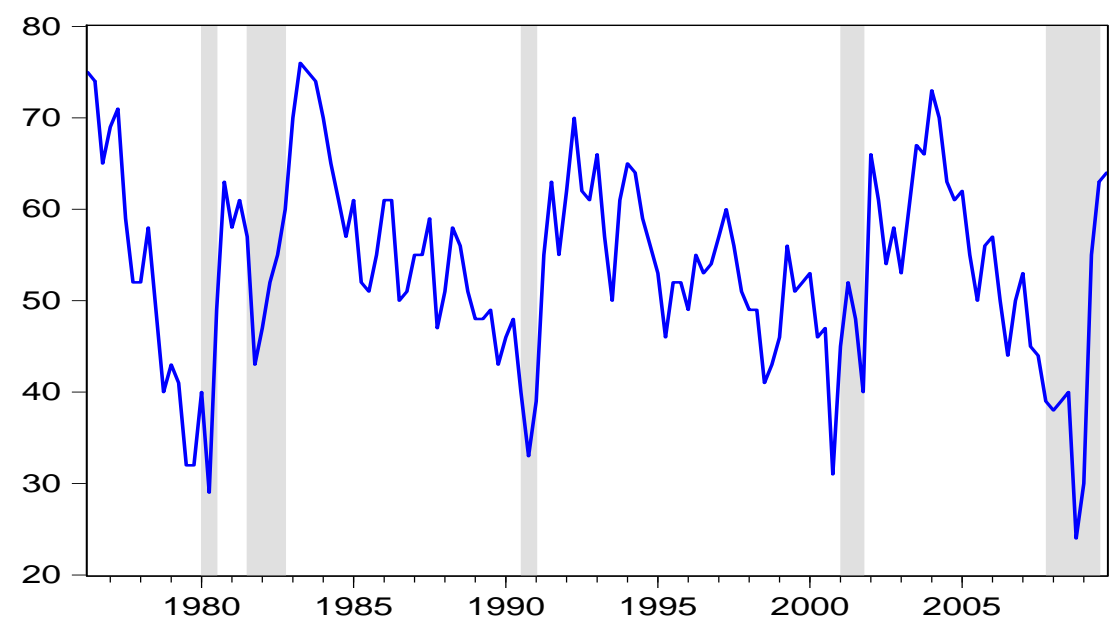

This figure plots the composite CEO confidence index from the Conference Board. Shaded gray areas are recessions as defined by the NBER. 
Figure 3: $f\left(z_{t}\right)$ Across Time

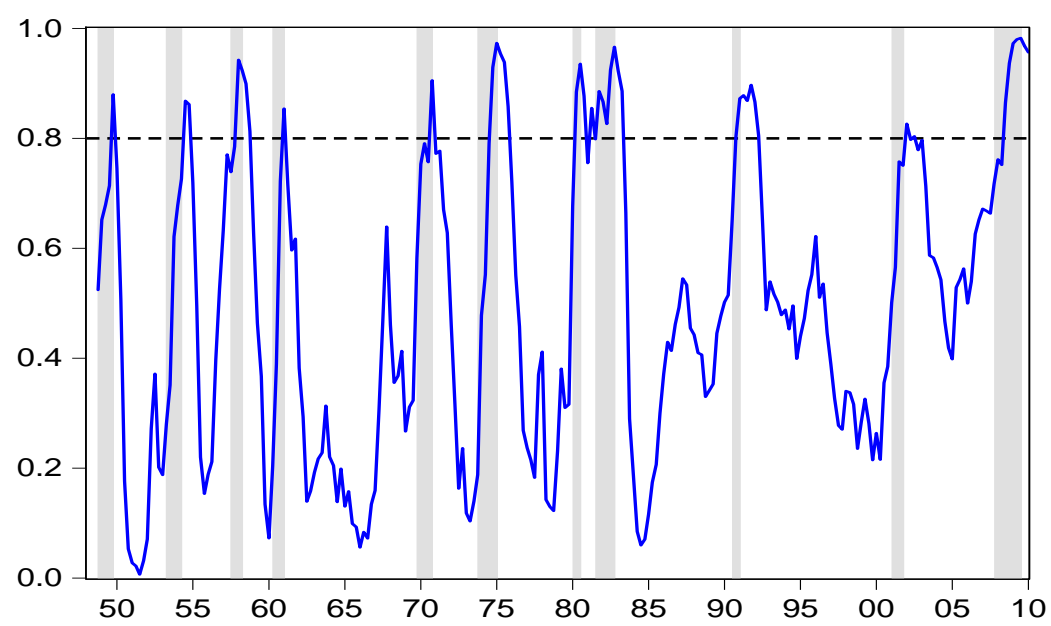

This figure plots the function $f\left(z_{t}\right)$, where $z_{t}$ is defined as the seven quarter moving average of real GDP growth. Shaded gray areas are recessions as defined by the NBER. The dashed black line is our cutoff for calling a period a "recession": $f\left(z_{t}\right)=0.8$. 
Figure 4: Model and Estimated Responses: RBC Case
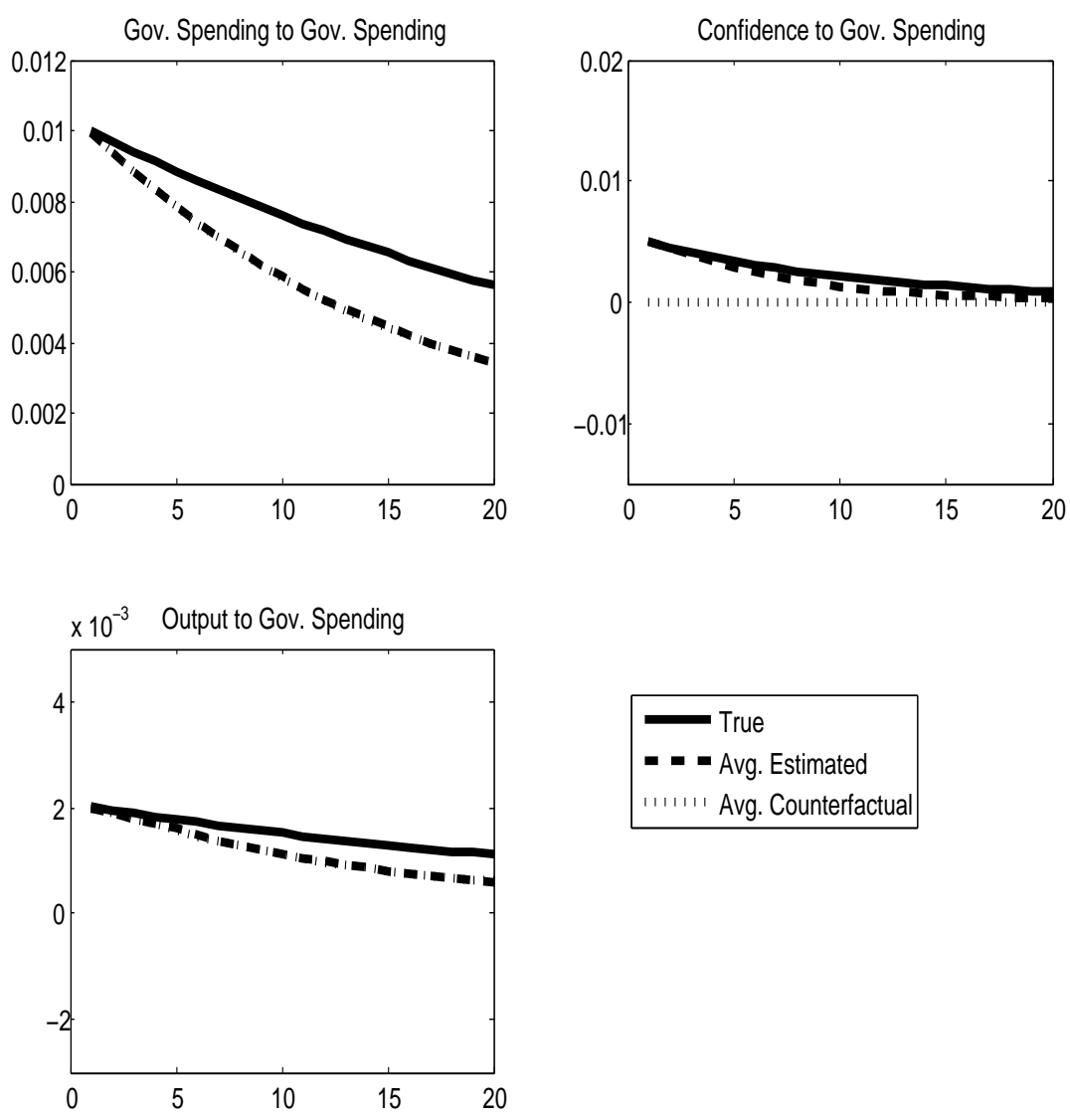

1 11111 Avg. Counterfactual

This figure shows theoretical and average estimated impulse responses to a government spending shock from a simple real business cycle model, as described in Section 3.3 of the text. 
Figure 5: Model and Estimated Responses: IRTS Case
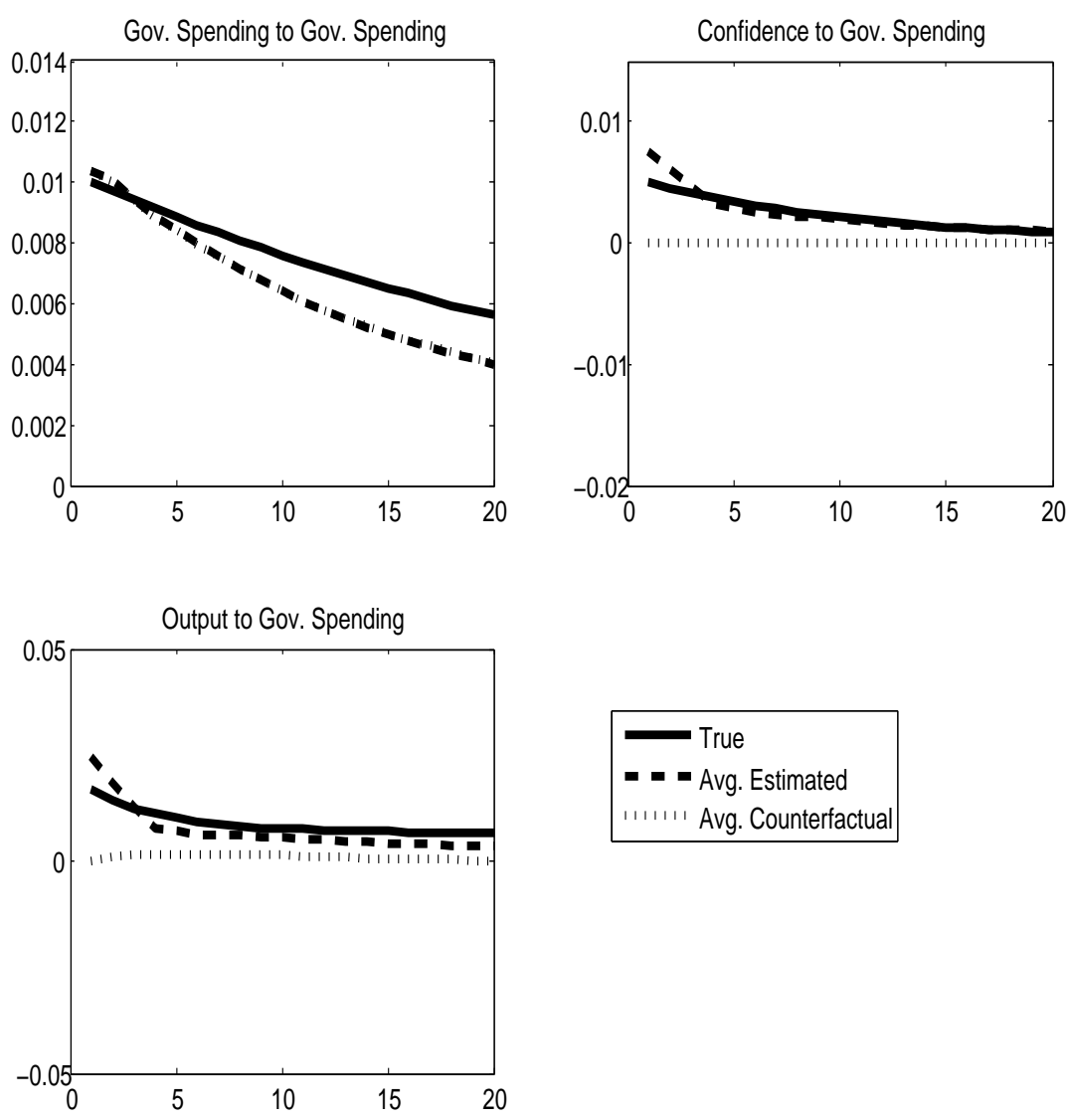

This figure shows theoretical and average estimated impulse responses to a government spending shock from a model with increasing returns to scale and multiple equilibria, as described in Section 3.3 of the text. 
Figure 6: Government Spending and Consumer Confidence
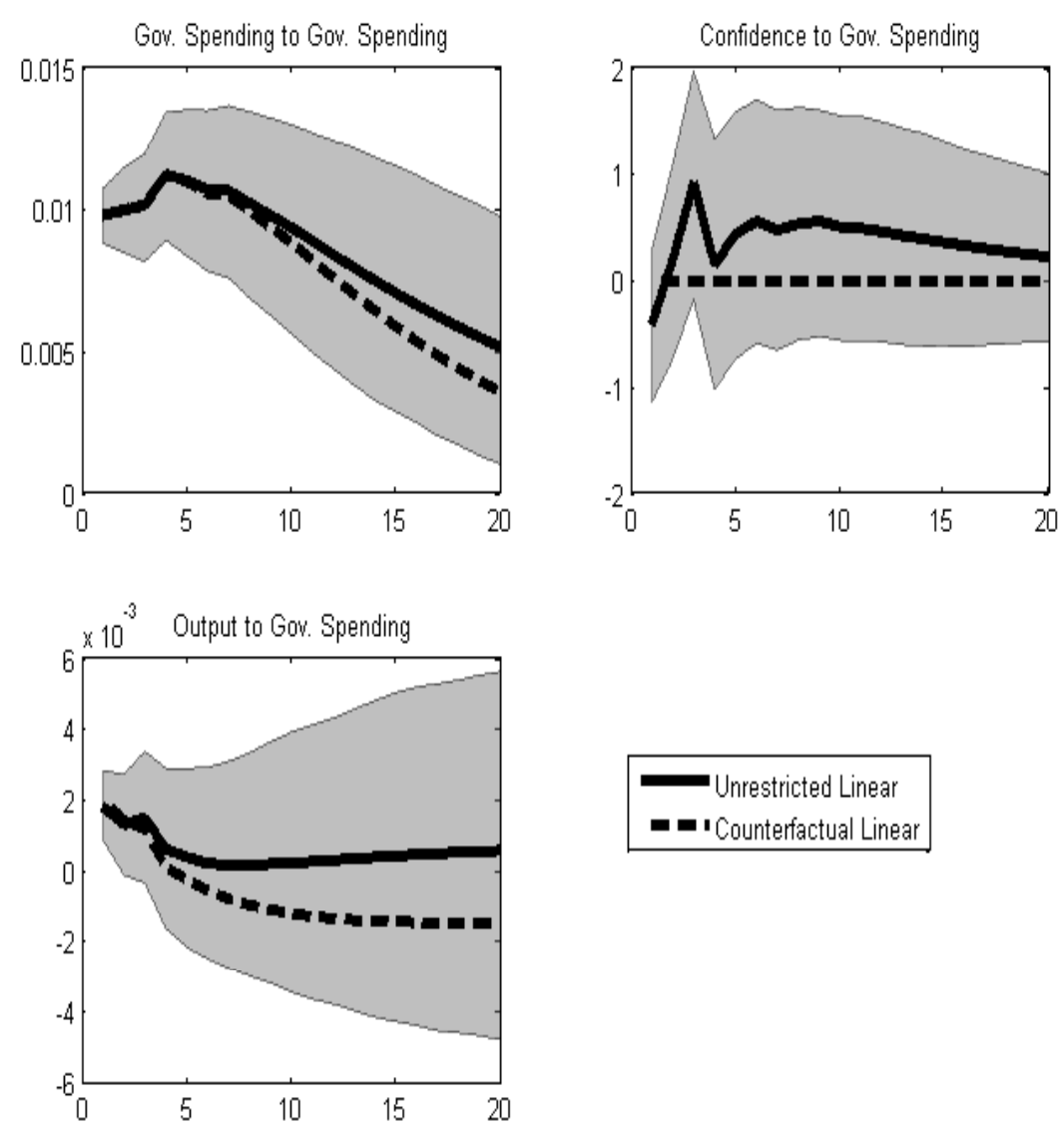

This figure shows impulse responses to a government spending shock from the benchmark system with government spending, consumer confidence, and real GDP. The solid lines are the estimated impulse responses. The shaded gray areas are confidence bands. The dashed lines are the counterfactual impulse responses when confidence is held fixed. 
Figure 7: Government Spending and CEO Confidence
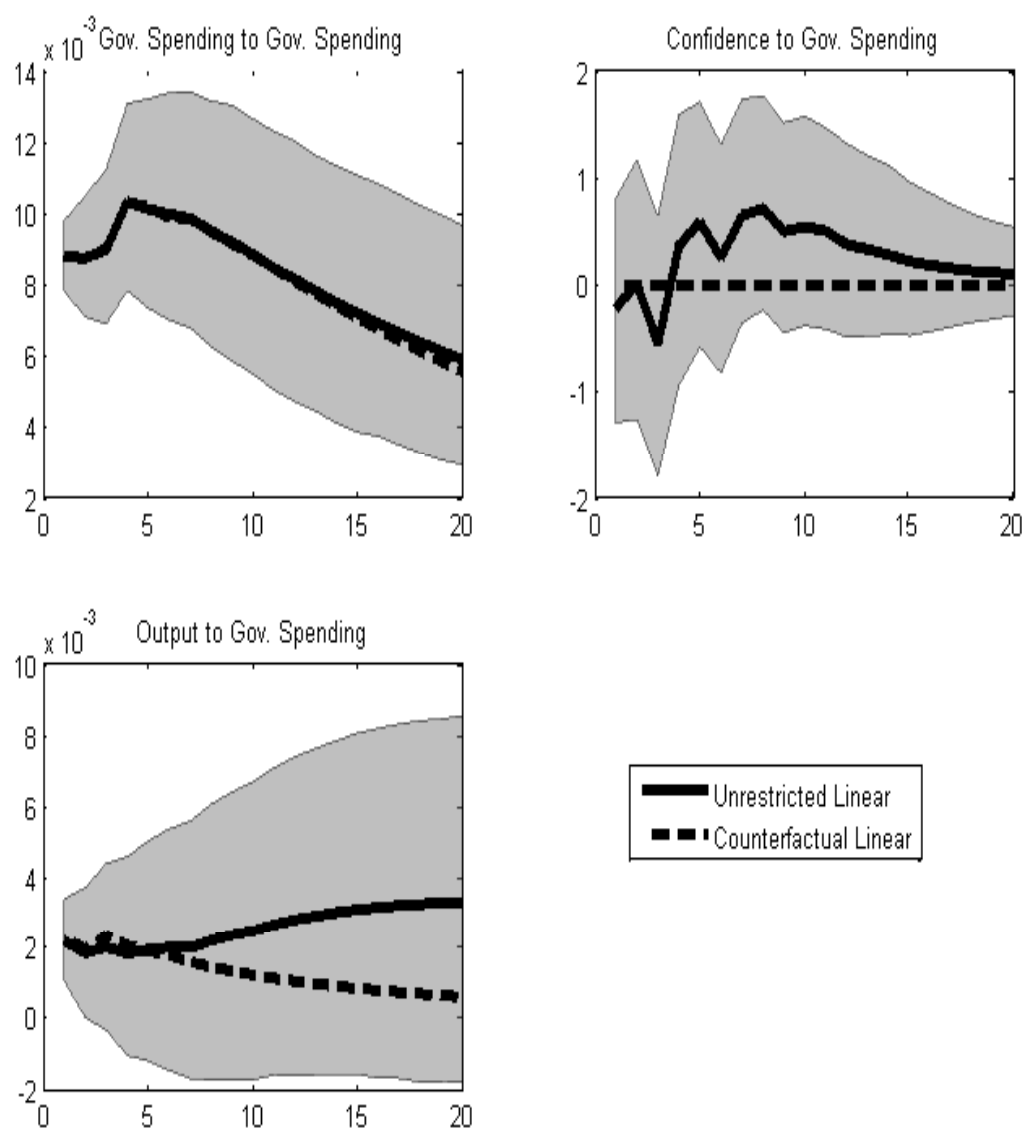

- $\mathbf{m}$ Counterfactual Linear

This figure shows impulse responses to a government spending shock from the benchmark system with government spending, ceo confidence, and real GDP. The solid lines are the estimated impulse responses. The shaded gray areas are confidence bands. The dashed lines are the counterfactual impulse responses when confidence is held fixed. 
Figure 8: Government Spending and Consumer Confidence: Recessions
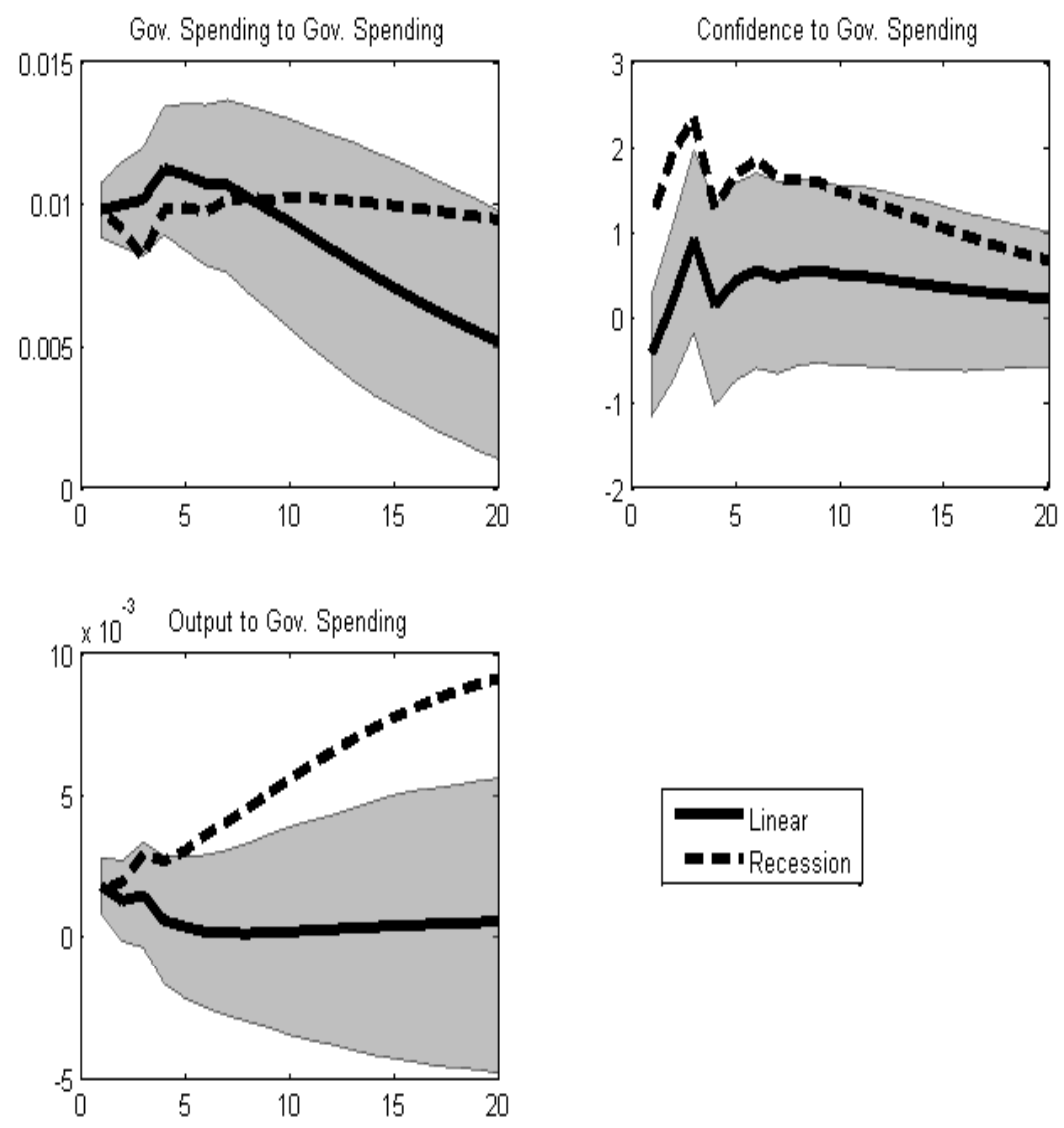

The dashed lines in this figure are impulse responses to a government spending shock in a recession from a non-linear system with government spending, consumer confidence, and real GDP. The solid lines are the estimated impulse responses from the linear system, and the shaded gray areas are the confidence bands from the linear system. 
Figure 9: Government Spending and CEO Confidence: Recessions
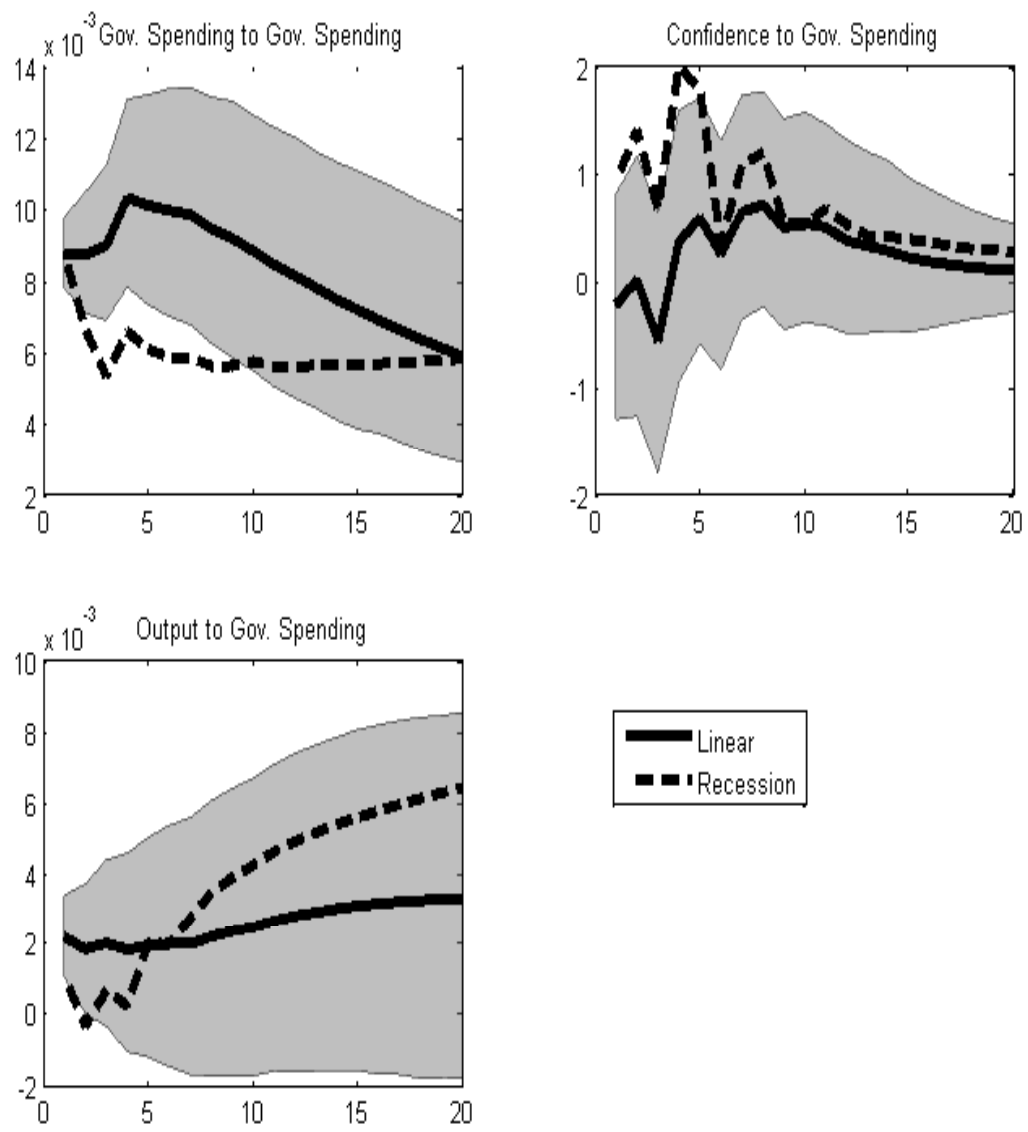

The dashed lines in this figure are impulse responses to a government spending shock in a recession from a non-linear system with government spending, CEO confidence, and real GDP. The solid lines are the estimated impulse responses from the linear system, and the shaded gray areas are the confidence bands from the linear system. 
Figure 10: Government Spending and Consumer Confidence: Recessions and Counterfactuals
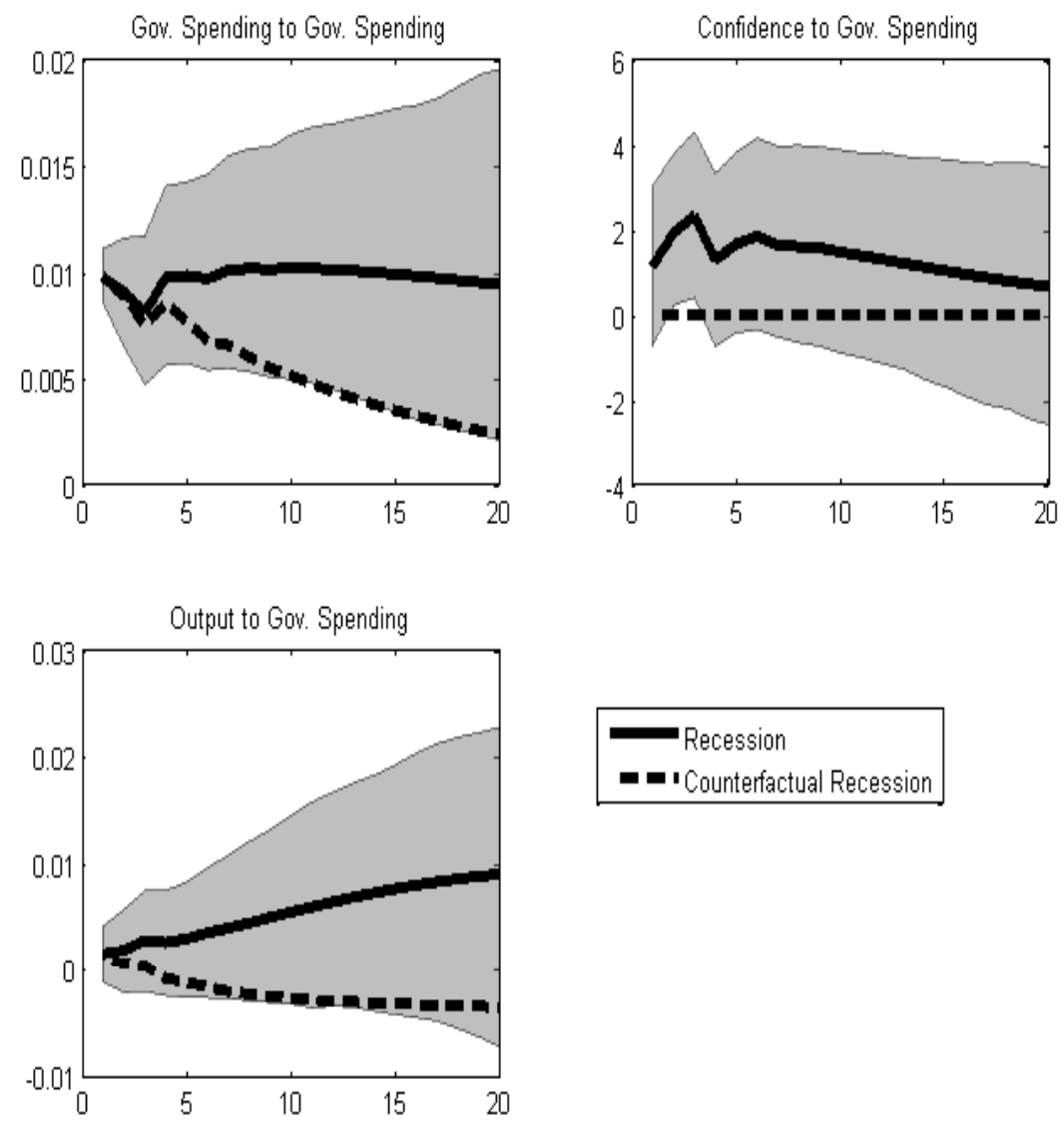

The solid lines in this figure are estimated impulse responses to a government spending shock in a recession. The shaded gray regions are the 90 percent confidence bands from a . . The dashed lines are the counterfactual impulse responses from shutting the response of confidence to spending down with offsetting confidence shocks. The underlying system features consumer confidence. 
Figure 11: Government Spending and CEO Confidence: Recessions and Counterfactuals
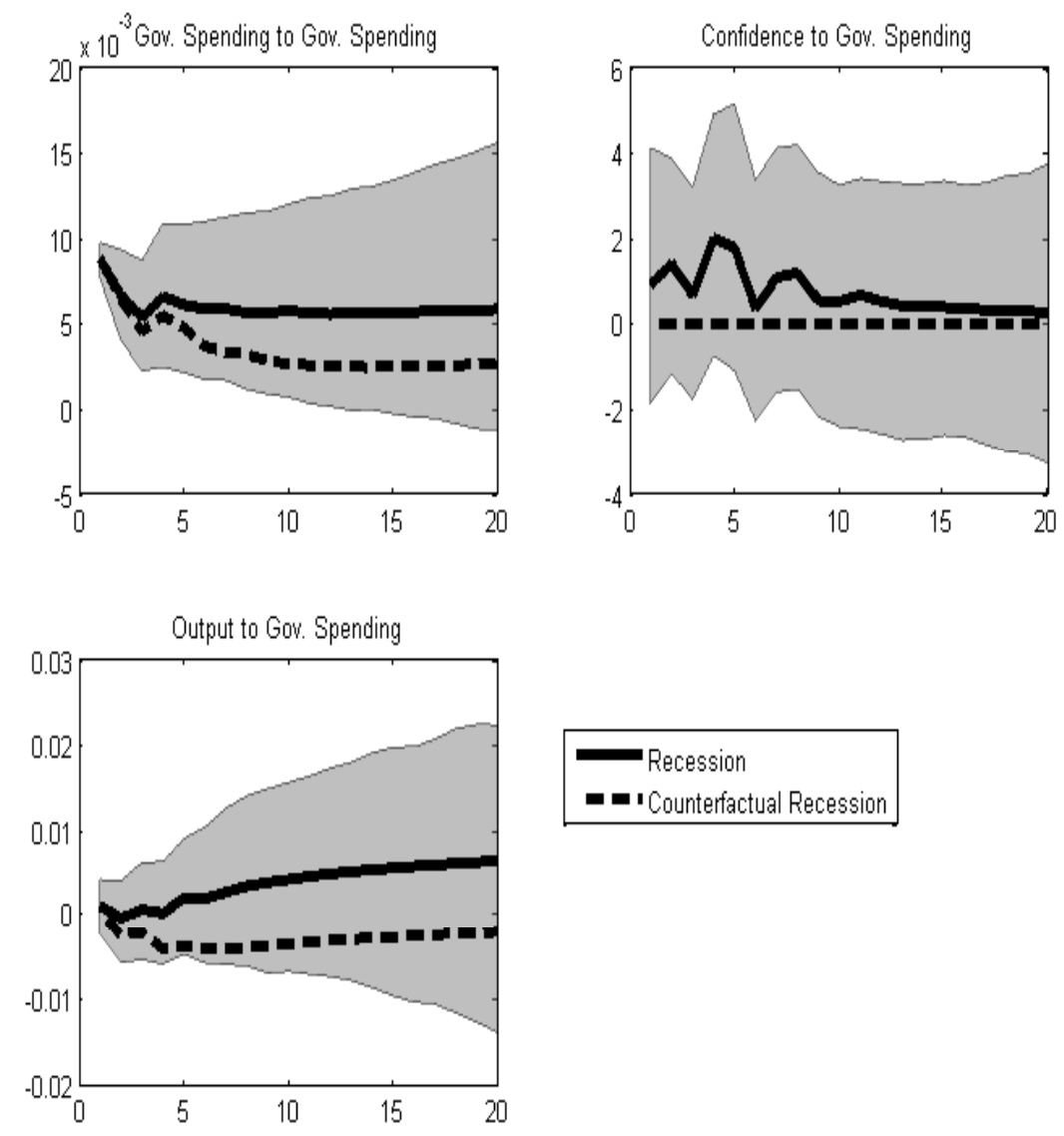

The solid lines in this figure are estimated impulse responses to a government spending shock in a recession. The shaded gray regions are the 90 percent confidence bands from a . . The dashed lines are the counterfactual impulse responses from shutting the response of confidence to spending down with offsetting confidence shocks. The underlying system features CEO confidence. 
Figure 12: Government Spending, Confidence, and Productivity
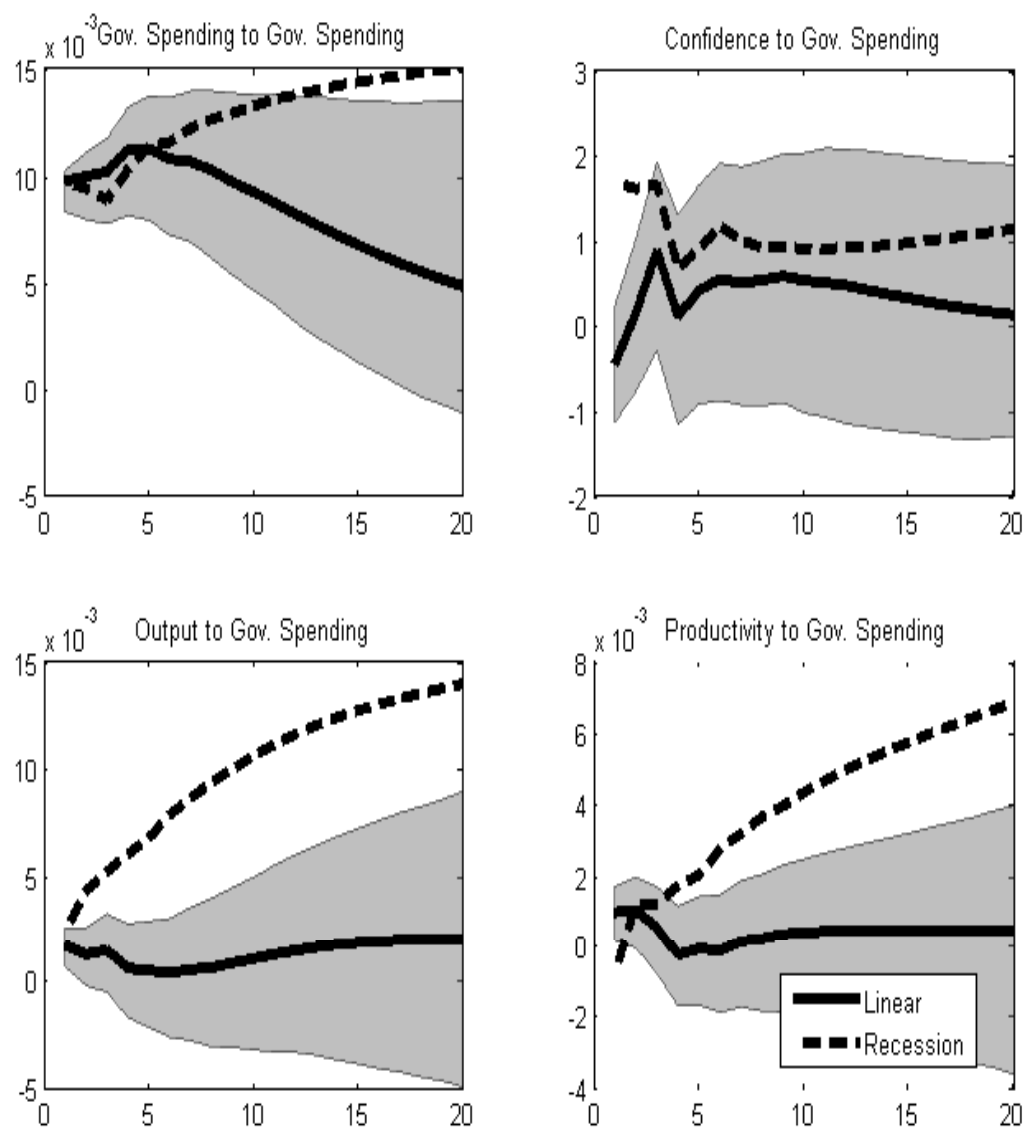

The underlying VAR features government spending, consumer confidence, real output, and labor productivity. The solid black lines are the impulse responses to a spending shock from the linear system; the shaded gray regions are the associated confidence bands. The dashed lines are the impulse responses to a spending shock in a recession. 
Figure 13: Government Spending, Confidence, and Productivity: Counterfactuals
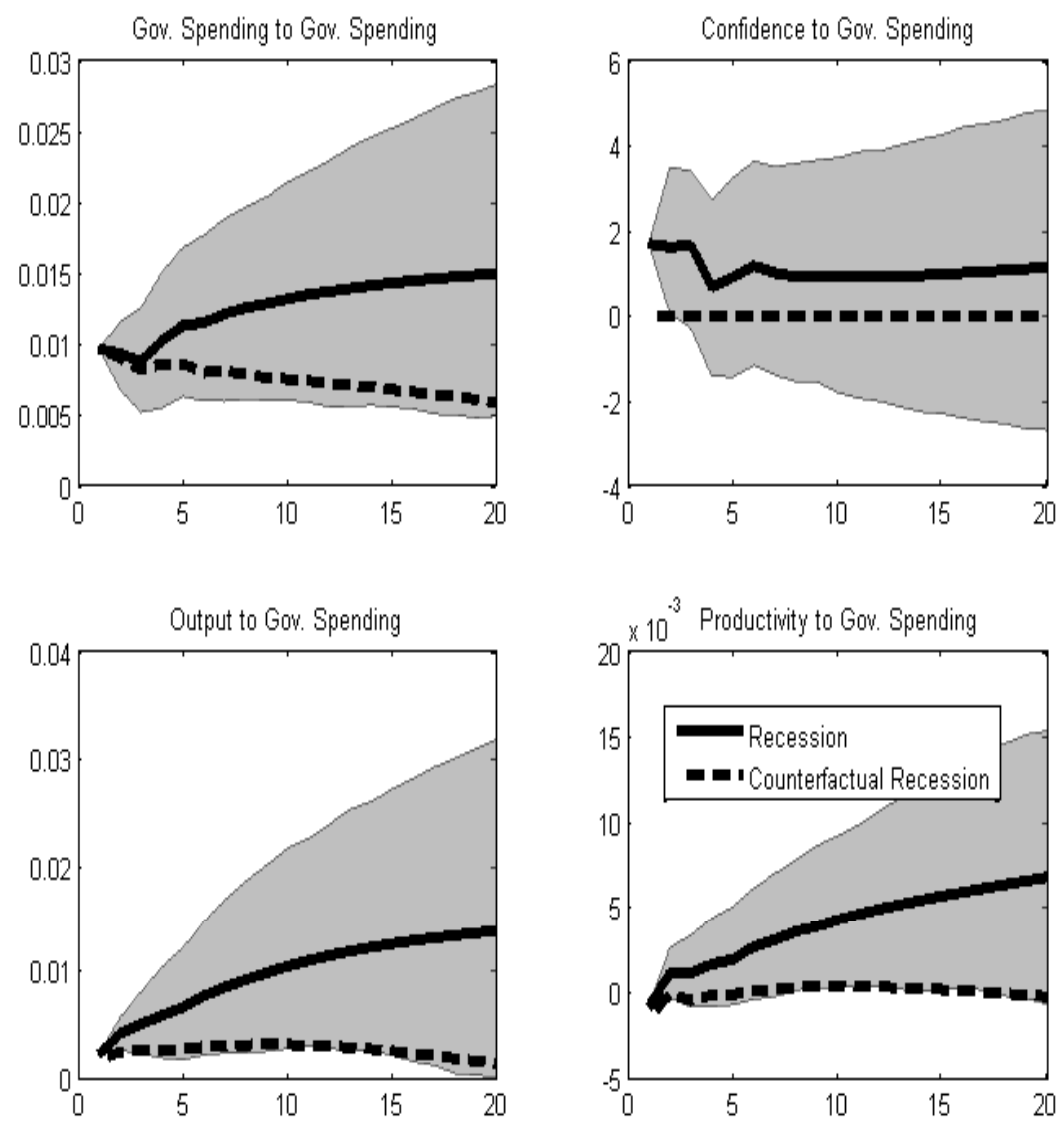

The underlying VAR features government spending, consumer confidence, real output, and labor productivity. The solid black lines are the estimated impulse responses in a recession and the shaded gray areas are the confidence bands. The dashed lines are the counterfactual impulse responses in which the confidence response is held fixed. 
Figure 14: Government Spending, Synthetic Confidence, and Productivity: Counterfactuals
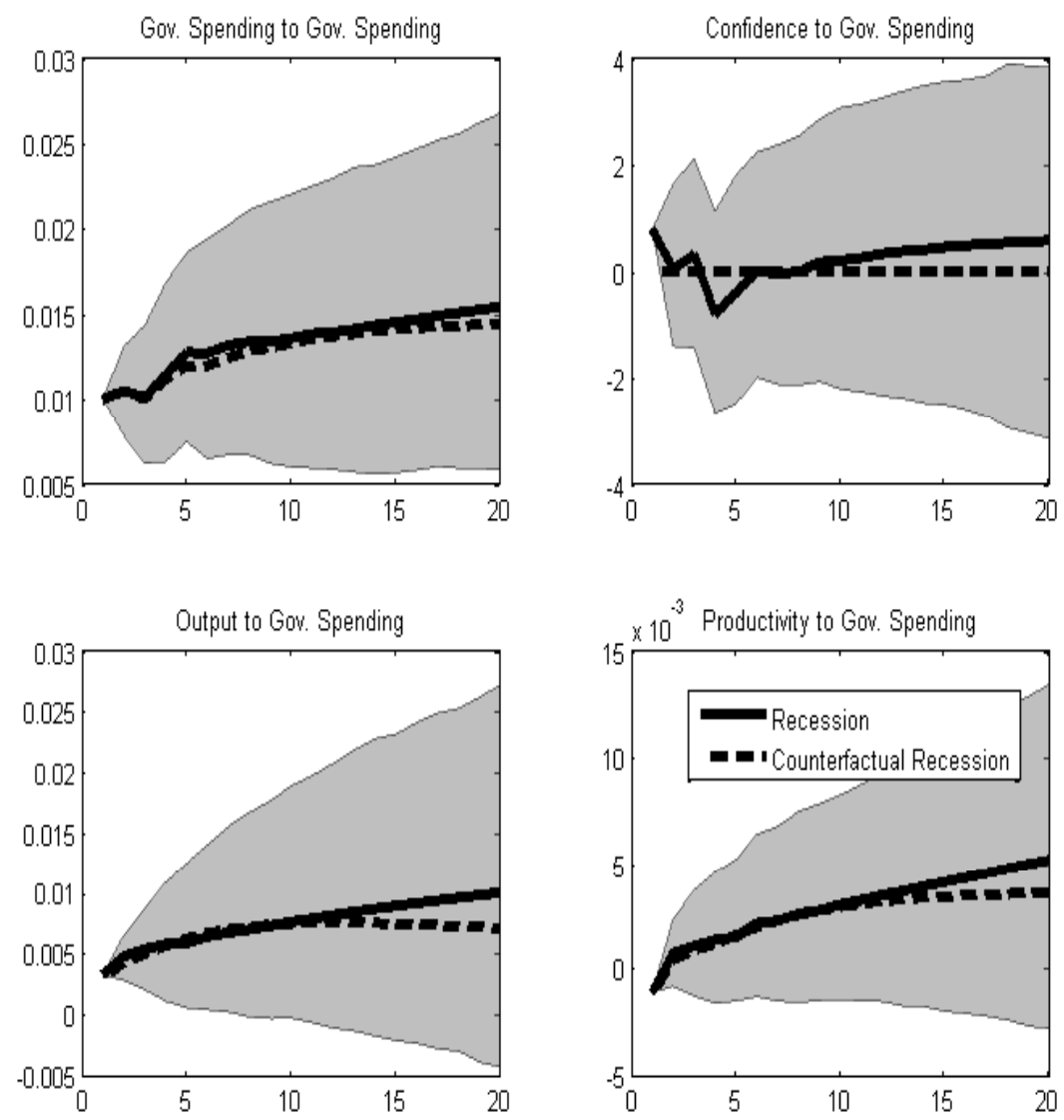

The underlying VAR features government spending, a synthetic consumer confidence, real output, and labor productivity. The synthetic confidence series is constructed such that there is no information about future productivity in it. The solid black lines are the estimated impulse responses in a recession and the shaded gray areas are the confidence bands. The dashed lines are the counterfactual impulse responses in which the confidence response is held fixed. 
Figure 15: Government Spending, Confidence, and Spending Components
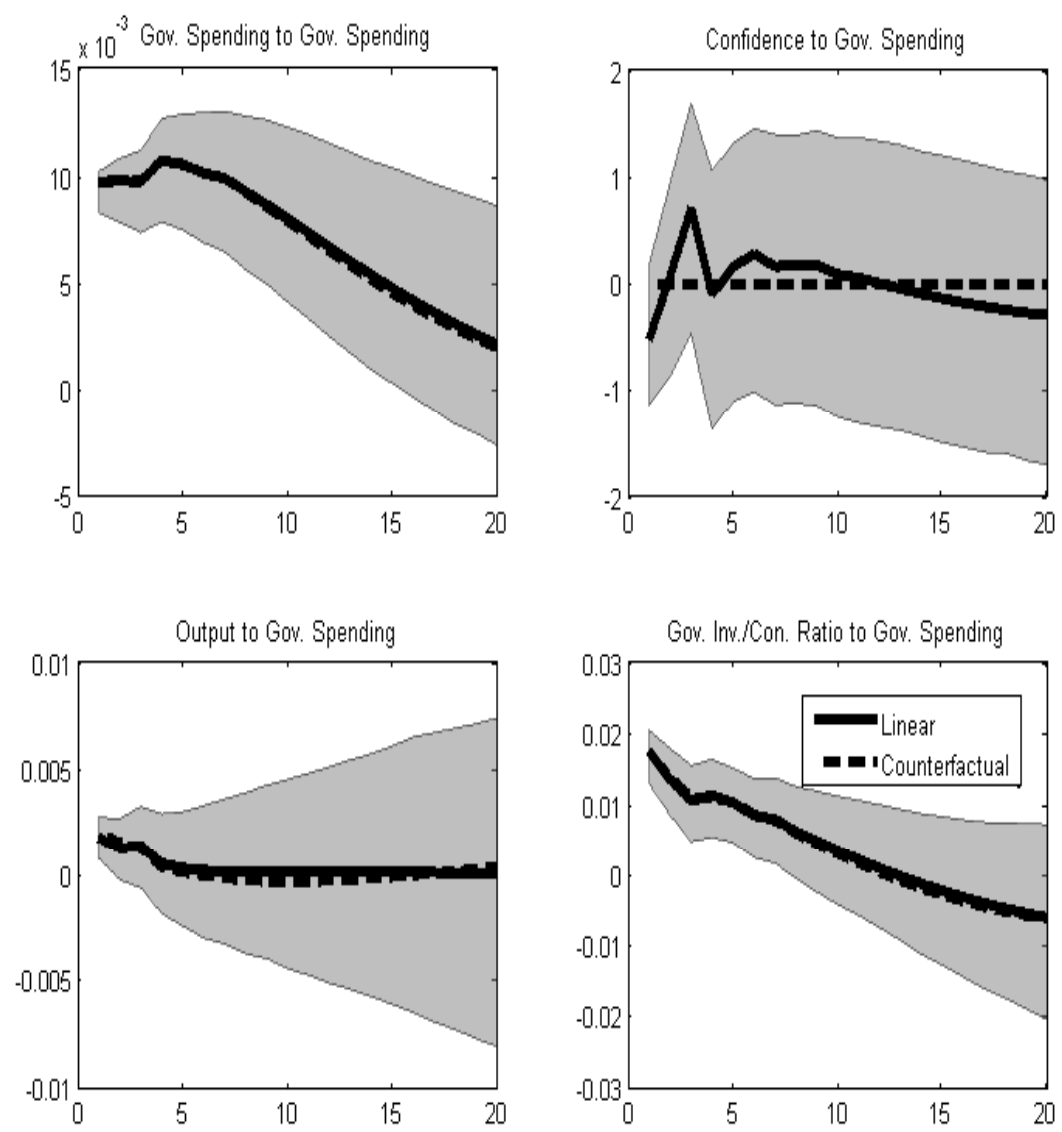

The underlying VAR features government spending, consumer confidence, real output, and the ratio of government investment to consumption expenditure. The solid black lines are the estimated impulse responses and the shaded gray areas are the confidence bands. The dashed lines are the counterfactual impulse responses in which the confidence response is held fixed. 
Figure 16: Government Spending, Confidence, and Spending Components
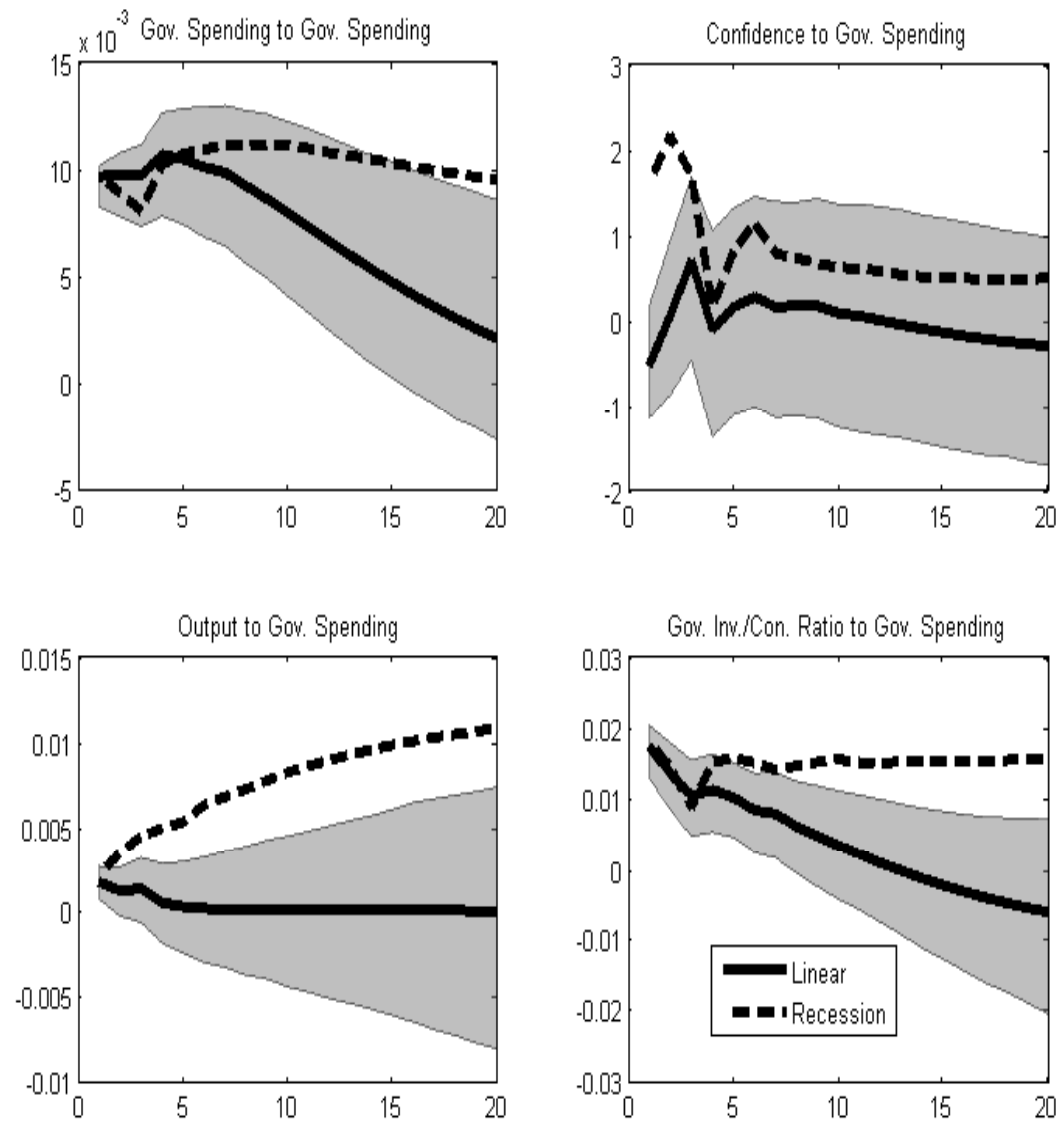

The underlying VAR features government spending, consumer confidence, real output, and the ratio of government investment to consumption expenditure. The solid black lines are the estimated impulse responses in the linear system and the shaded gray areas are the confidence bands. The dashed lines are the estimated responses in a recession. 
Figure 17: Government Spending, Confidence, and Spending Components: Counterfactuals
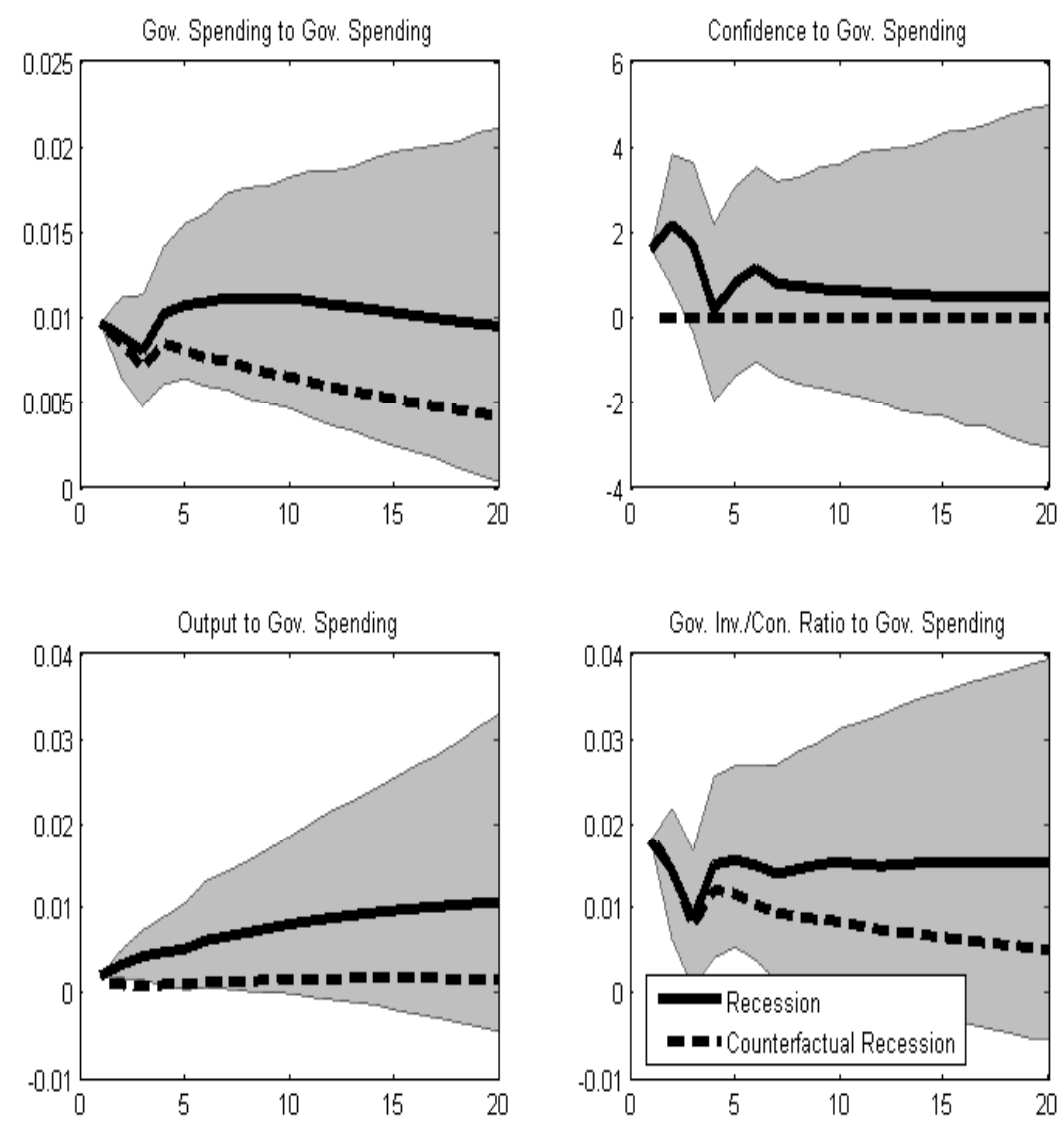

The underlying VAR features government spending, consumer confidence, real output, and the ratio of government investment to consumption expenditure. The solid black lines are the estimated impulse responses in a recession and the shaded gray areas are the confidence bands. The dashed lines are the estimated counterfactual responses when confidence is held fixed. 